\title{
Cross-sectional behaviour of cold-formed high strength steel circular hollow sections
}

\author{
Xin Meng", Leroy Gardner \\ Department of Civil and Environmental Engineering, Imperial College London, London, UK \\ ${ }^{*}$ Corresponding author. Tel.: +44 (0)77 51579750 \\ E-mail address: xin.meng15@imperial.ac.uk
}

\begin{abstract}
A comprehensive experimental and numerical study into the cross-sectional behaviour of structural steel circular hollow sections (CHS), with an emphasis on high strength steel, is presented in this paper. Six cold-formed high strength steel S700 CHS profiles $-168.3 \times 4,139.7 \times 4,139.7 \times 5,139.7 \times 6,139.7 \times 8$ and $139.7 \times 10$ (diameter $\times$ thickness, in $\mathrm{mm})$, spanning from Class 1 to Class 4 in compression according to EN 1993-1-1, were experimentally examined. The test programme consisted of twelve tensile coupon tests, local geometric imperfection measurements, six stub column tests, six four-point bending tests, six three-point bending tests and fifteen short beam-column tests. In parallel with the experimental study, finite element (FE) models of CHS were established and validated against the obtained experimental results, and parametric studies were subsequently carried out using the developed models to expand the cross-sectional resistance data pool. Finally, the cross-section design provisions specified in the European code prEN 1993-1-1:2018 and the American Specification ANSI/AISC 360-16 were assessed using the freshly generated experimental and numerical results as well as the existing test data on hotrolled and cold-formed CHS from the literature. The present study provides the basis for the development of improved cross-section design rules for normal and high strength steel CHS in future research.
\end{abstract}


Keywords: ANSI/AISC 360-16; Circular hollow sections (CHS); Cold-formed; Cross-sectional design; Digital image correlation (DIC); EN 1993-1-1; High strength steel; Laboratory testing; Numerical simulation.

\section{Introduction}

High strength steels, with grades over S460, offer a variety of benefits over conventional strength steels in structural applications; their high strength-to-weight ratio enables smaller and lighter structural components, resulting in lower transportation and handling costs, more design possibilities for highrise and long-span structures and reduced overall carbon emissions [1]. High strength steel products are gaining increasing use in the construction industry, with prominent examples including the National Stadium (the Bird's Nest) in Beijing (Fig. 1(a)) and the Nesenbach Valley Bridge in Stuttgart (Fig. 1(b)). Two types of heat treatment - quenching and tempering and thermomechanical rolling, are commonly used to produce high strength steels, allowing an increase in the material strength without overly compromising on ductility, weldability and toughness [4]. With advances in production technology, high strength structural steel products with yield strength as high as $1300 \mathrm{MPa}$ are now commercially available.

Structural hollow sections are popular among the range of steel profiles available to structural engineers, offering excellent performance in compression, high torsional resistance and an aesthetic appearance. High strength steel hollow sections combine the benefits from both high strength steels and hollow sections and have experienced significant development in recent years. High strength steel tubular sections are readily available as hot-finished and cold-formed products, as standardised in EN 102102:2006 [5] and EN 10219-2:2006 [6] respectively; welded box sections can also be fabricated by welding four high strength steel plates at their corners. Currently, Eurocode $3[7,8]$ is applicable to high strength steels up to grade S700, while the Chinese code GB 50017-2017 [9] provides design rules up to grade Q460. The latest American Specification ANSI/AISC 360-16 [10] covers steel plates with nominal yield strengths up to $690 \mathrm{MPa}$ [11], while for hollow structural sections, only those with 
nominal yield strengths up to $485 \mathrm{MPa}$ [12] can be designed using this specification. Similarly, the Australian standard AS 4100-1998 Rec:2016 [13] is applicable to steel plates with yield strength up to $690 \mathrm{MPa}$, while hollow sections with yield strength in excess of $450 \mathrm{MPa}$ are beyond the scope of this standard. Generally, in these design codes, the rules for high strength steels are essentially a simple extension to those for normal strength steels.

Extensive research on high strength steel hollow sections has been carried out in recent years to understand better their structural behaviour and to develop improved design rules. The cross-sectional behaviour of high strength steel tubular sections has been investigated experimentally by a number of researchers: Jiao and Zhao [14] and Ma, Chan and Young [15] tested a series of cold-formed CHS, Wang et al. [16] and Meng and Gardner [17] examined hot-rolled square and rectangular hollow sections (SHS and RHS), Ma, Chan and Young [15] and Wang et al. [16] studied cold-formed SHS and RHS, Rasmussen and Hancock [18] and Schillo and Feldmann [19] investigated welded box sections and Fang, Chan and Young [20] explored octagonal hollow sections. A number of experimental studies were also dedicated to the global buckling behaviour of high strength steel tubular members, such as Ban et al. [21], Pournara et al. [22], Somodi and Kovesdi [23], and Wang and Gardner [24]. Overall, however, experimental data on high strength steel hollow sections are still relatively scarce, and further test and numerical data are considered necessary to expand the current database for the assessment and improvement of structural design provisions.

A comprehensive experimental and numerical study into the cross-sectional behaviour of cold-formed high strength steel circular hollow sections (CHS) has been conducted and is presented in this paper. A series of cross-section tests were firstly carried out. Six CHS profiles were examined, ranging from Class 1 to Class 4 (in compression) according to the latest revision to EN 1993-1-1 [25]. The test programme included twelve tensile coupon tests, six stub column tests, six four-point bending tests, six three-point bending tests and fifteen short beam-column tests, along with local geometric imperfection measurements for the tested CHS specimens. In parallel with the laboratory testing, a numerical simulation programme was conducted. Finite element (FE) models were established and validated against the obtained test results, and were then used for parametric studies to generate additional cross- 
section resistance data over a wider range of material properties, cross-section geometries and load combinations. Finally, the obtained experimental and numerical results, combined with the existing test data collected from the literature, were utilised to assess the suitability of the cross-section design rules for CHS in Eurocode 3 and AISC 360.

\section{Experimental investigation}

\subsection{General}

A comprehensive experimental programme was conducted in the Structures Laboratory at Imperial College London to investigate the cross-sectional behaviour of cold-formed high strength steel circular hollow sections (CHS). Six CHS, all cold-formed from the thermomechanically rolled S700MC steel sheets [26], were examined; the nominal cross-section sizes (outer diameter $D \times$ thickness $t$ ) and the section ID are listed in Table 1. The tested sections cover Class 1 to Class 4 in compression and Class 1 to Class 3 in bending according to the latest local slenderness limits set out in prEN 1993-1-1:2018 $[25,27,28]$, as also shown in Table 1 . The chemical composition and the mechanical properties of the tested profiles, as provided in the mill certificates, are given in Tables 2 and 3 respectively. Overall, the test programme included twelve tensile coupon tests (TC), six stub column tests (SC), six four-point bending tests (4B), six three-point bending tests (3B) and fifteen short beam-column tests (SBC), covering the load cases of axial compression, uniform bending, bending with a moment gradient and combined loading. Each test specimen was labelled with an identifier, e.g. CSBC3-2, where C denotes the cross-section shape (CHS), SBC denotes the test type (see the acronyms given previously), 3 represents the cross-section ID (see Table 1) and 2 is the test ID (omitted if there was only one test in the series).

\subsection{Material tests}

The stress-strain relationships and key mechanical properties of the tested materials were obtained through tensile coupon tests. In total, twelve tensile coupons, with two for each section, were prepared 
and tested. The coupon specimens were dimensioned in accordance with EN ISO 6892-1:2016 [29] and extracted longitudinally at $90^{\circ}$ to the welding seam. A series of overlapping standard gauge lengths of $5.65 \sqrt{S_{0}}$ were scribed onto both faces of the coupons for the determination of the percentage elongations at fracture [29], where $S_{0}$ is the cross-sectional area of the coupon in the parallel length.

The tensile tests were performed using an Instron $250 \mathrm{kN}$ hydraulic testing machine, as shown in Fig. 2. A pair of linear electrical resistance strain gauges were attached to the centre of both sides of the coupons to measure the axial strain, and an Instron video extensometer was used simultaneously to monitor the average strain over a gauge length of $140 \mathrm{~mm}$ within the parallel length. To prevent the gripping jaws from squashing the ends of the coupons and introducing any loading eccentricity, high strength metal-filled epoxy putty was applied to the concave side of the gripped ends of the coupons, as shown in Fig. 3. Concentricity of loading was confirmed by the uniformity of the increments in strain on the two faces of the coupons. Note that the coupon specimens exhibited significant initial longitudinal curvatures upon extraction from the CHS (see Fig. 4) due to the release of bending residual stresses. As the coupons were straightened during testing, the bending residual stresses were reintroduced and were therefore inherently incorporated into the stress-strain relationships obtained from the tensile coupon tests.

The hydraulic testing machine was driven under displacement control. The crosshead separation rates were chosen such that a strain rate of $0.007 \% \mathrm{~s}^{-1}$ up to the $0.2 \%$ proof stress and of $0.025 \% \mathrm{~s}^{-1}$ beyond yielding was achieved, with a gradual ramp between them to avoid any abrupt change in rate. The video extensometer recorded at 0.1 -second intervals using the fully integrated modular software package Bluehill 2 [30], while the loads and strain gauge readings were recorded at 0.33 -second intervals using the data acquisition equipment DATASCAN and logged using the DSLOG software.

The obtained engineering stress-strain curves are plotted in Fig. 5, and the key mechanical properties, including the Young's modulus $E$, the yield strength $f_{\mathrm{y}}$ (taken as the $0.2 \%$ proof stress), the ultimate tensile strength $f_{\mathrm{u}}$ and the strain at the ultimate strength $\varepsilon_{\mathrm{u}}$, are reported in Table 4 . The obtained stressstrain curves exhibited the typical rounded characteristics associated with cold-formed steels. In terms 
of ductility, the tested materials were less ductile than normal strength steels, as revealed by the ductility indices $f_{\mathrm{u}} / f_{\mathrm{y}}, \varepsilon_{\mathrm{u}} / \varepsilon_{\mathrm{y}}$ and $\varepsilon_{\mathrm{f}}$ in Table 4 ; this is particularly evident for the three sections with the lower diameter-to-thickness ratios, i.e. CHS $139.7 \times 6$, CHS $139.7 \times 8$ and CHS $139.7 \times 10$, due principally to the higher level of cold-working induced during the manufacturing process.

\subsection{Local geometric imperfection measurements}

Local geometric imperfections inevitably exist in structural elements and can influence the initiation of plasticity, the onset of local buckling and the ultimate cross-section capacity. In this experimental study, measurements of local geometric imperfections were carried out for all 21 CHS stub column and short beam-column specimens. The test setup is shown in Fig. 6, which is similar to those setups adopted by Schafer and Pekoz [31] and Gardner et al. [32]. The specimens were seated on a pair of V-shaped blocks that were precisely aligned and clamped onto the bed of a milling machine. This allowed the specimens to be moved longitudinally by the milling machine, with a linear variable displacement transducer (LVDT) held in the head of the milling machine used to record geometric deviations at $2 \mathrm{~mm}$ intervals. Meanwhile, a string pot was employed to monitor the longitudinal displacement. For each specimen, the measurements were carried out along twelve equally spaced longitudinal lines (i.e. at $30^{\circ}$ intervals) around the circumference. The LVDT and string pot readings were recorded using the data acquisition equipment DATASCAN and logged using the DSLOG software.

Typical measured deviations are displayed in Fig. 7 (with outward deviations positive), where the black and red lines represent the deviations at $90^{\circ}$ and $180^{\circ}$ to the weld respectively. End flaring can be clearly seen from the results, which stemmed from the release of bending residual stresses; similar observations for cold-formed hollow sections were also reported by [32,33]. Therefore, only the data within the central $80 \%$ of the member length $L$ were used for analysis of the local imperfection distributions. Linear regression analysis was performed for each set of data, and deviations with respect to the fitted line were considered as the local geometric imperfections. For each specimen, the maximum deviation of all twelve measurements was taken as the local imperfection amplitude $\omega_{1}$. 


\subsection{Stub column tests}

Stub column tests were conducted to investigate the cross-sectional behaviour of the specimens under axial compression. A total of six stub column tests, one on each of the studied CHS profiles, were performed. The nominal length of the stub columns was chosen as three times the outer diameter, as recommended by [34]; this length was short enough to avoid global buckling but still sufficiently long to include a representative pattern of local imperfections and residual stresses. Both ends of the specimens were machined flat and square to avoid a non-uniform distribution of compressive stresses during testing. The measured geometric properties of the stub column specimens, along with the corresponding local slendernesses $D / t \varepsilon^{2}$, are summarised in Table 5, where $D$ is the outer diameter, $t$ is the wall thickness, $L$ is the member length and $\varepsilon^{2}=235 / f_{\mathrm{y}}$.

The compression tests were performed using an Instron $3500 \mathrm{kN}$ hydraulic testing machine. The adopted experimental setup is shown in Fig. 8. The stub columns were compressed between the two parallel end platens of the testing machine whereby fixed boundary conditions were achieved. Hardened end plates were placed between the platens and the specimens to avoid damage to the testing machine from the high localised stresses. Steel ring stiffeners that were precisely machined to match the outer diameter of the tested tubes were mounted at each end of the specimens to prevent any cross-section distortion or local bending at the end sections. The axial deformation was monitored by four strain gauges attached to the mid-height of the specimens at $90^{\circ}$ intervals and four LVDTs positioned around the perimeter, as illustrated in Fig. 8. The stub column tests were conducted under displacement control at a constant rate of $0.5 \mathrm{~mm} / \mathrm{min}$. The test outputs, including the load, machine displacement, strain gauge readings and LVDT readings, were recorded at 0.5 -second intervals using the data acquisition equipment DATASCAN and logged using the DSLOG software; the same data recording technique was also adopted in the short beam-column tests and beam tests, as presented in the following subsections.

The normalised load-end shortening curves, with the load $N$ normalised by the plastic load $N_{\text {pl }}$ (equal to $A f_{\mathrm{y}}$, where $A$ is the cross-sectional area) and the end shortening $\delta$ normalised by the elastic end- 
shortening at the plastic load $\delta_{\mathrm{pl}}$ (Eq. (1)), are plotted in Fig. 9. The key test results, including the ultimate axial load $N_{\mathrm{u}}$, the end shortening at the peak load $\delta_{\mathrm{u}}$ and the ratio of $N_{\mathrm{u}}$ to $N_{\mathrm{pl}}$, are reported in Table 5. Note that the true end shortening was obtained by eliminating the elastic deformation of the end plates from the LVDT measurements using the strain gauge data following the recommendations of [35-37]. Typical failure modes of the tested CHS stub columns are presented in Fig. 10. All the stub columns failed by the formation of a bulge near either the top or bottom end except CSC5 and CSC6, for which bulges developed at both ends and one dominated later in the post-ultimate range. An increasing susceptibility to local buckling with higher local slenderness (i.e. from CSC6 to CSC1) is clearly seen from the normalised load-deformation curves in Fig. 10. The tested CHS, despite two being classified as Class 4 in compression, were all capable of carrying an axial load above $N_{\mathrm{pl}}$ by at least $11.1 \%$.

$$
\delta_{\mathrm{pl}}=\frac{f_{\mathrm{y}} L}{E}
$$

\subsection{Four-point bending tests}

Four-point bending tests were performed to study the moment resistance and rotation capacity of each CHS profile under uniform moment; in total, six four-point bending tests were conducted. The measured cross-section dimensions and the local slendernesses are summarised in Table 6.

The four-point bending tests were performed using an Instron $2000 \mathrm{kN}$ hydraulic testing machine, with the test configuration shown in Fig. 11. The 2000 mm-long beam specimens were seated symmetrically on a pair of roller supports positioned at a distance between the centres of the rollers of $1850 \mathrm{~mm}$. The vertical load from the hydraulic actuator was transferred through a spreader beam to two steel rollers (with one fixed to restrain the longitudinal movement of the specimens) as two equal vertical point loads. The distance between the centres of the two loading rollers was set to $720 \mathrm{~mm}$ for the CHS $168.3 \times 4$ beam and $600 \mathrm{~mm}$ for the remainder, thereby achieving a flexural span of approximately four times the outer diameter of the test specimens. In order to avoid localised failure under the concentrated loading, saddle-shaped steel seats were situated between the rollers and the specimens at the two loading points and two support points, with rubber sheets placed between the seats and specimens to spread the 
load. Wooden blocks were precisely machined and inserted into the specimens at the loading points to further strengthen the loaded regions. The instrumentation employed in the four-point bending tests consisted of two strain gauges on the top and bottom fibres of the specimens in the flexural span, three LVDTs to measure the vertical displacements at the centre and two ends of the flexural span and four inclinometers to measure the rotations at the loading and support points. Additionally, digital image correlation (DIC) was employed, whereby a speckle pattern was applied to the flexural span of the beams, and a two-camera StrainMaster DIC system from LaVision was used to monitor the development of strain and displacement throughout testing. The bending tests were carried out under displacement control at a vertical displacement rate of $2.5 \mathrm{~mm} / \mathrm{min}$. The same data acquisition approach as for the stub column tests was used, while for the DIC, the images were taken at 2-second intervals and processed using DaVis 10 [38].

The normalised moments $M / M_{\mathrm{pl}}$ are plotted against the normalised curvatures $\kappa / \kappa_{\mathrm{pl}}$ obtained from the beam tests in Fig. 12, where the following symbols are used: $M_{\mathrm{pl}}=W_{\mathrm{p} f} f_{\mathrm{y}}$ is the plastic moment resistance, $W_{\mathrm{pl}}$ is the plastic section modulus, $\kappa$ is the average curvature in the flexural span, $\kappa_{\mathrm{pl}}$ is the elastic curvature at $M_{\mathrm{pl}}$, as calculated using Eq. (2), and $I$ is the second moment of area.

$$
\kappa_{\mathrm{pl}}=\frac{M_{\mathrm{pl}}}{E I}
$$

Table 6 summarises the key experimental results including the ultimate bending moment $M_{\mathrm{u}}$, the average curvature at the ultimate moment $\kappa_{\mathrm{u}}$ and the rotation capacity $R$, as defined in Fig. 13 and calculated from Eq. (3), where $\kappa_{\mathrm{pl}, \mathrm{u}}$ is the average curvature when the applied moment drops back to $M_{\mathrm{pl}}$. As illustrated in Fig. 14, the applied moment in the flexural span $M$ consists of the moments induced by both the horizontal and vertical components of the applied forces, as calculated using Eq. (4), in which all parameters are annotated in Fig. 14.

$$
\begin{gathered}
R=\frac{\kappa_{\mathrm{pl}, \mathrm{u}}}{\kappa_{\mathrm{pl}}}-1 \\
M=F_{\mathrm{V}} L_{\mathrm{V}}+F_{\mathrm{H}, 1} L_{\mathrm{H}, 1}-F_{\mathrm{H}, 2} L_{\mathrm{H}, 2}
\end{gathered}
$$


The average curvature in the flexural span $\kappa$ was calculated from the LVDT readings using Eq. (5) for the initial stage, where $d_{\mathrm{L}}$ is the average vertical displacement from the two LVDTs under the loading points, $d_{\mathrm{M}}$ is the vertical displacement at mid-span and $L_{\mathrm{f}}$ is the length of the flexural span.

$$
\kappa=\frac{8\left(d_{\mathrm{L}}-d_{\mathrm{M}}\right)}{4\left(d_{\mathrm{L}}-d_{\mathrm{M}}\right)^{2}+L_{\mathrm{f}}^{2}}
$$

With the development of ovalisation and onset of local buckling, the curvature within the flexural span became increasingly non-uniform, and the inclinometer readings were utilised instead to calculate the average curvature, as given by Eq. (6), where $\theta_{\mathrm{f}, 1}$ and $\theta_{\mathrm{f}, 2}$ are the rotations from the inclinometers at the two loading points.

$$
\kappa=\frac{\theta_{\mathrm{f}, 1}+\theta_{\mathrm{f}, 2}}{L_{\mathrm{f}}}
$$

All the four-point bending specimens failed within the flexural span, with no discernible localised deformation from the concentrated loading at the loading and support points. A typical local buckling failure mode for the CHS in uniform bending is displayed in Fig. 15. Local buckling was observed in all specimens except Specimens C4B5 and C4B6, for which the tests were terminated before the initiation of local buckling. For Specimens C4B1 and C4B2, local buckling was accompanied by an abrupt loss of load-carrying capacity, as seen in the moment-curvature curves, while for Specimens C4B3 to C4B6, the peak moments were reached due to the combined effects of material yielding and ovalisation. Typical DIC results, for Specimen C4B4, are shown in Fig. 16, where the development of strain prior to and after local buckling can be observed. The six tested CHS beams, including those classified as Class 3 in bending, were all capable of attaining their plastic moment capacity $M_{\mathrm{pl}}$ under the uniform applied bending moment.

\subsection{Three-point bending tests}

In addition to the four-point bending tests, three-point bending tests were also carried out on the CHS to study their structural responses under moment gradients. A total of six three-point bending tests, one 
test on each CHS profile, was performed. The measured cross-section dimensions and the local slendernesses are reported in Table 7.

The three-point bending tests were performed using a similar test setup to that for the four-point bending tests but with a modified loading configuration, as shown in Fig. 17. A fixed roller was mounted directly beneath the hydraulic jack in place of the spreader beam to transfer the vertical load to the mid-span of the specimens. Similarly, in order to prevent localised failure under the concentrated loading, saddleshaped steel seats, rubber sheets and wooden blocks were employed at the mid-span and the ends of the beam specimens. Note that the wooden block and the steel seat at the mid-span had the same length of $90 \mathrm{~mm}$, leading to a fully stiffened region of $90 \mathrm{~mm}$ at the mid-span and a shear span of length $L_{\mathrm{s}}=880$ $\mathrm{mm}$ on each side. Strain gauges were attached to the top and bottom fibres of the specimens at a distance of $140 \mathrm{~mm}$ from the mid-span. An LVDT was mounted beneath the mid-span to measure the vertical deflection, and three inclinometers were used to monitor the rotations at the mid-span and two ends of the beams. DIC was also employed to monitor the regions near the mid-span. The three-point bending tests were carried out at a vertical displacement rate of $3 \mathrm{~mm} / \mathrm{min}$. The data acquisition system was the same as for the four-point bending tests.

The obtained normalised moment-rotation curves are plotted in Fig. 18, with the maximum bending moment in the shear span $M$ normalised by $M_{\mathrm{pl}}$ and the average end rotation $\theta$ normalised by the elastic end rotation at the plastic moment $\theta_{\mathrm{pl}}$ (Eq. (7)).

$$
\theta_{\mathrm{pl}}=\frac{M_{\mathrm{pl}} L_{\mathrm{s}}}{2 E I}
$$

The key test results are summarised in Table 7, where $\theta_{\mathrm{u}}$ is the end rotation at $M_{\mathrm{u}}$ and $R$ is the rotation capacity. The rotation capacity for three-point bending tests is defined in Fig. 13 and Eq. (8), where $\theta_{\mathrm{pl}, \mathrm{u}}$ is the average end rotation when the applied maximum moment drops back to $M_{\mathrm{pl}}$.

$$
R=\frac{\theta_{\mathrm{pl}, \mathrm{u}}}{\theta_{\mathrm{pl}}}-1
$$


The maximum bending moment in the shear span $M$, as illustrated in Fig. 19, was calculated using Eq. (9) incorporating the moments introduced from both the vertical force $F_{\mathrm{V}}$ and the horizontal force $F_{\mathrm{H}}$, with all parameters annotated in Fig. 19.

$$
M=F_{\mathrm{V}} L_{\mathrm{V}}+F_{\mathrm{H}} L_{\mathrm{H}}
$$

All specimens failed by local buckling in the highest moment region close to the mid-span, as shown in

Fig. 15. Note that the bending test for Specimen C3B6 was terminated after the peak moment was reached but before the occurrence of discernible local buckling. All the examined CHS were capable of attaining $M_{\mathrm{pl}}$ under the applied moment gradients, and the ultimate moments were, on average, $8.2 \%$ higher than their counterparts under uniform moment due to the combined benefits of the moment gradient and the stiffening effect from the mid-span.

\subsection{Short beam-column tests}

Short beam-column tests were conducted with the aim of investigating the local buckling response and load-carrying capacity of the CHS under combined compression and bending. In total, fifteen short beam-column tests were carried out, with five on each of the CHS $168.3 \times 4$, CHS $139.7 \times 4$ and CHS $139.7 \times 5$ profiles. The nominal length of the specimens was taken as three times the outer diameter, as for the stub columns. The measured dimensions and local imperfection amplitudes of the short beamcolumn specimens are summarised in Table 8.

The combined loading tests were conducted in an Instron $2000 \mathrm{kN}$ hydraulic testing machine, as shown in Fig. 20. Different combinations of compression and bending were achieved through the application of a compressive force at varying initial loading eccentricities. A pair of knife edges was employed at the top and bottom ends of the test specimens, whereby pin-ended boundary conditions were provided. The test specimens were welded onto a pair of thick end plates and bolted eccentrically onto the wedge plates; the thicknesses of the end plates $t_{\mathrm{ep}}$ are listed in Table 8. The initial loading eccentricities were carefully measured, as reported in Table 8 , where $e_{\mathrm{n}}$ and $e_{\mathrm{m}}$ are the nominal and measured initial loading eccentricities respectively. Strain gauges were attached to the mid-height of the specimens at the most compressive and tensile (or least compressive) fibres. The mid-height lateral deflections were measured 
using an LVDT on the tensile (or least compressive) side, and the end rotations were monitored using two inclinometers attached to the top and bottom wedge plates. A four-camera StrainMaster DIC system from Lavision was employed for selected tests, with two cameras focussed on one side of the specimens perpendicular to the axis of bending and two focussed on the most heavily compressed region of the specimens. The short beam-column tests were performed under displacement control at a constant rate of $0.5 \mathrm{~mm} / \mathrm{min}$. The test data were recorded and logged in the same manner as in the stub column tests, while the DIC images were recorded at 0.5-second intervals and processed using DaVis 10 [38].

The load-mid-height lateral deflection curves and load-average end rotation curves from the short beamcolumn tests are plotted in Fig. 21, and the key experimental results are summarised in Table 8, where $N_{\mathrm{u}}$ is the peak load, $\Delta_{\mathrm{u}}$ and $\varphi_{\mathrm{u}}$ are the mid-height lateral deflection and end rotation at the peak load respectively and $M_{\text {tot,u }}$ is the total bending moment (first + second order) at the peak load. The secondorder moment was incorporated into the total bending moment $M_{\text {tot }}$ through Eq. (10), where $\Delta$ is the lateral deflection at mid-height. Considering that the examined CHS are classified as either Class 3 or 4 under the considered combined loading conditions and the onset of local buckling generally coincided with the attainment of the peak load, the peak load $N_{u}$ and the corresponding total moment $M_{\text {tot } u}$ were taken as the cross-section failure loads herein [17].

$$
M_{\text {tot }}=N\left(e_{\mathrm{m}}+\Delta\right)
$$

All the short beam-columns failed by local buckling on the most compressed side of the cross-section, with a typical failure mode displayed in Fig. 22. The strain and out-of-plane displacement fields obtained from the DIC data for Specimen CSBC3-4, together with the corresponding load-mid-height lateral deflection curve, are shown in Fig. 23, where the development of local buckling and the deformed shape in the post-ultimate regime can be clearly seen. 


\section{Numerical simulations}

\subsection{General}

In parallel with the experimental programme, a numerical simulation study was conducted. The finite element (FE) models of the CHS were initially established and validated against the experimental results for compression, bending and combined loading. Parametric studies were subsequently carried out using the validated models to generate further numerical cross-sectional resistance data for CHS.

\subsection{Description of FE models}

Geometrically and materially nonlinear analyses with imperfections (GMNIA) were performed using Abaqus [39] to simulate the cross-sectional behaviour of CHS under various loading scenarios. The four-node shell element with reduced integration - S4R, was adopted as the element type [40]. A mesh of element size equal to $0.1 \sqrt{D t}$, which is approximately $8 \%$ of the axisymmetric elastic buckling halfwavelength in compression $\lambda_{\mathrm{cl}}$ (as given by Eq. (11), where $r$ is the radius of the CHS) and $6 \%$ of the elastic buckling half-wavelength in bending $\lambda$ (as given by Eq. (12)), was employed; this adopted mesh was shown to be fine enough to capture the local buckling behaviour of CHS but still maintain good computational efficiency. Symmetry about the mid-length plane and the plane perpendicular to the axis of bending was exploited by creating quarter-models of the CHS members; this technique has been successfully adopted in previous numerical studies, such as [41-43]. Note that for the four-point bending specimens, only the flexural span was simulated. All degrees of freedoms at the end sections were coupled to a reference point where suitable boundary conditions, mirroring the test conditions, were applied.

$$
\begin{aligned}
& \lambda_{\mathrm{cl}} \approx 1.728 \sqrt{r t} \\
& \lambda \approx 2.444 \sqrt{r t}
\end{aligned}
$$

Suitable local geometric imperfections were incorporated into the FE models following the recommendations of [44]. The elastic buckling mode obtained from a linear bifurcation analysis (LBA) of the modelled geometry, but with a modified thickness $t_{\mathrm{mod}}=D / 5$ (referred to as the LBA- $t_{\mathrm{mod}}$ mode), 
was used to represent the local imperfection pattern; this method was shown to yield consistent mode shapes and avoid unrealistically short wavelengths, which is observed in the LBA results of real geometry (referred to as the LBA- $t$ mode) for CHS with relatively high $D / t$ values. A predictive formula for the local imperfection amplitude $\omega_{1}$ of CHS, as developed by Meng and Gardner [44] and described by Eq. (13), was used to scale the imperfection pattern in this study. A comparative study of different local imperfection patterns and amplitudes was carried out as part of the model validation and is presented in the following subsection.

$$
\omega_{1}=0.01 \sqrt{D t}
$$

Residual stresses arise in cold-formed sections due to coiling and uncoiling, rolling and welding and in hot-rolled sections due to uneven cooling. However, the dominant bending residual stresses for coldformed sections are inherently incorporated into the stress-strain relationships obtained from the tensile coupon tests, while for hot-rolled hollow sections, the residual stresses are typically very low in magnitude compared with the yield strength $[45,46]$. Therefore, explicit inclusion of residual stresses into the FE models was deemed unnecessary for both the hot-rolled and cold-formed CHS.

\subsection{Validation}

The developed FE models were validated against the obtained experimental results on cold-formed CHS in terms of the ultimate loads, load-deformation curves and failure modes [47]. The measured geometric and material properties were used in the models. Four groups of FE analyses were considered: (a) geometrically and materially nonlinear analyses with no imperfection (GMNA), (b) GMNIA with the LBA- $t_{\text {mod }}$ imperfection pattern factored by $\omega_{1}$ from Eq. (13), (c) GMNIA with the LBA- $t$ imperfection pattern factored by $\omega_{1}$ from Eq. (13) and (d) GMNIA with the LBA- $t_{\text {mod }}$ imperfection pattern factored by the measured $\omega_{1}$. The test ultimate loads $N_{\mathrm{u}, \text { test }}$ and $M_{\mathrm{u} \text {,test }}$ were compared with those obtained from the FE models $N_{\mathrm{u}, \mathrm{FE}}$ and $M_{\mathrm{u}, \mathrm{FE}}$ for the various imperfection types under the different loading scenarios, as summarised in Table 9, where COV is the coefficient of variation. The FE resistances obtained using the LBA- $t$ imperfection pattern were shown to be unduly sensitive to the local imperfection amplitude $\omega_{1}$, particularly for the cases of bending and combined loading. The numerical ultimate loads obtained 
using the LBA- $t_{\text {mod }}$ pattern, on the other hand, were relatively insensitive to $\omega_{1}$ and provided accurate predictions of the test ultimate loads with both the predicted and measured imperfection amplitudes $\omega_{1}$. Excellent agreement was also observed from the comparisons of the experimental and numerical (with LBA- $t_{\text {mod }}$ pattern and $\omega_{1}$ from Eq. (13)) load-deformation curves and failure modes, as displayed in Figs 24 and 25. Overall, the developed FE models were capable of accurately replicating the cross-sectional responses of the CHS observed in the experiments, and are therefore considered to be suitable for use in parametric studies.

\subsection{Parametric studies}

Having developed and validated the CHS FE models, parametric studies were conducted to generate additional cross-sectional resistance data over a wider range of material properties, cross-section sizes and load combinations. Hot-rolled and cold-formed CHS with five different steel grades (S355, S460, S550, S690/S700 and S900) were examined; the stress-strain curves were derived from the predictive models of [48] and [49] for the hot-rolled and cold-formed steel CHS respectively. The input parameters of the predictive models, including the Young's modulus $E$, the yield strength $f_{\mathrm{y}}$ and the ultimate strength $f_{\mathrm{u}}$, were taken according to the nominal values specified in prEN 1993-1-1:2018 [25] (S700 and below) and the predictive formulae in $[48,49]$ (above S700).

The outer diameter $D$ of the modelled cross-sections was set to $100 \mathrm{~mm}$, with the thickness $t$ varied to achieve a wide spectrum of local slenderness from $D / t \varepsilon^{2}=7.6$ to 402.1 (i.e. $D / t=0.008 E / f_{\mathrm{y}}$ to $0.45 E$ $\left(f_{\mathrm{y}}\right)$. Three load cases - pure compression, uniform bending and combined compression plus bending, were simulated through the stub column, four-point bending and short beam-column models respectively. The modelled lengths of the stub column and short beam-column models were set equal to three times the outer diameter, while the modelled flexural span $L_{\mathrm{f}}$ for the beam models was chosen corresponding to a dimensionless length $\Omega$ (as defined by Eq. (14)) of 7, which is deemed sufficiently long to account for the ovalisation effect [42].

$$
\Omega=\frac{L_{\mathrm{f}}}{r} \sqrt{\frac{t}{r}}
$$


For each modelled cross-section, nine initial loading eccentricities were considered to capture the full trend of the cross-section interaction behaviour under combined compression plus bending. In total, 1650 cross-sectional resistance data on CHS, including 150 in compression, 150 in uniform bending and 1350 under combined loading, were generated from this numerical simulation programme.

\section{Existing codified cross-section design provisions for CHS}

\subsection{General}

The codified cross-section design provisions for steel circular hollow sections, as specified in the upcoming version of Eurocode 3 (denoted by EC3) - prEN 1993-1-1:2018 [25], and the current American Specification (denoted by AISC) - ANSI/AISC 360-16 [10], are presented herein. Note that

partial safety factors are employed in both design codes to ensure an appropriate level of reliability. A partial safety factor of $\gamma_{\mathrm{M} 0}=1.0$ is employed in EC3, while in AISC, the partial factors $\phi_{\mathrm{c}}$ and $\phi_{\mathrm{b}}$ for compression and bending respectively are set equal to 0.9 .

\subsection{Eurocode 3-prEN 1993-1-1:2018}

In the current version of Eurocode 3, the design provisions for normal strength steel (S460 or below) are given in EN 1993-1-1:2005 [7], while the supplementary rules for high strength steel (S460-S700), which are generally a simple extension of the provisions in EN 1993-1-1:2005 [7], are given in EN 1993-1-12:2007 [8]. In the upcoming revision to EC3, the structural design rules for steels up to and including grade S700 are given in prEN 1993-1-1:2018 [25], while those for grades higher than S700 will be covered in the future revision to EN 1993-1-12. The latest cross-section design rules for CHS in prEN 1993-1-1:2018 [25] are outlined below.

Cross-sections are initially placed into one of four classes based on their susceptibility to local buckling. Class 1 cross-sections are defined as those that can reach and maintain their fully plastic section resistances with sufficient rotation capacity for the formation of plastic hinges and the redistribution of 
moments in plastic design. Class 2 cross-sections are also capable of achieving their fully plastic section resistances but do not have sufficient deformation capacity for plastic design. Class 3 cross-sections are able to attain their first yield capacities but fail by local buckling before the fully plastic section resistance is developed; for Class 4 sections, failure occurs prior to the attainment of the capacity at first yield due to the early onset of local buckling. The current slenderness limits in EN 1993-1-1:2005 [7] and the upcoming limits in prEN 1993-1-1:2018 [25] for CHS are listed together in Table 10 for comparison purposes, where the limits are presented in terms of both $D / t \varepsilon^{2}$ and $D / t$ based on Eq. (15), assuming that $E=210000 \mathrm{~N} / \mathrm{mm}^{2}$, and $\psi$ is the ratio of the minimum stress to the maximum stress over the cross-section depth (with compression positive) assuming an elastic stress distribution. Note that the Class 3 limits for bending and combined loading are due to be relaxed in prEN 1993-1-1:2018 [25] according to the recommendations of $[27,28,43]$.

$$
D / t \varepsilon^{2}=\frac{D}{t} \frac{f_{\mathrm{y}}}{235} \frac{210000}{E}=\frac{210000}{235} \frac{D}{t} \frac{f_{\mathrm{y}}}{E}
$$

The cross-section design equations in prEN 1993-1-1:2018 [25] are summarised in Table 11. Note that $\gamma_{\mathrm{M} 0}$ is the partial safety factor and is equal to 1.0 , and the subscripts Ed and Rd denote the design value of the applied load and the design value of the resistance respectively. For the load case of pure axial compression, the cross-section design resistance to axial compression $N_{\mathrm{c}, \mathrm{Rd}}$ is equal to the plastic section resistance $N_{\mathrm{pl}, \mathrm{Rd}}=A f_{\mathrm{y}} / \gamma_{\mathrm{M} 0}$ for Class 1 to $3 \mathrm{CHS}$ and is equal to the design effective section resistance $N_{\text {eff,Rd }}=A_{\text {efff }} f_{\mathrm{y}} / \gamma_{\mathrm{M} 0}$ for Class 4 CHS, where $A_{\text {eff }}$ is the effective cross-sectional area.

For Class 1 and 2 CHS in pure bending, the design moment resistance $M_{\mathrm{c}, \mathrm{Rd}}$ is equal to the plastic moment resistance $M_{\mathrm{pl}, \mathrm{Rd}}=W_{\mathrm{p} l} f_{\mathrm{y}} / \gamma_{\mathrm{M} 0}$, where $W_{\mathrm{pl}}$ is the plastic section modulus. For Class 3 CHS, the design moment resistance can be taken as either the conventional elastic moment resistance $M_{\mathrm{el}, \mathrm{Rd}}=$ $W_{\mathrm{el}} f_{\mathrm{y}} / \gamma_{\mathrm{M} 0}$ or the elasto-plastic moment resistance $M_{\mathrm{ep}, \mathrm{Rd}}=W_{\mathrm{ep}} f_{\mathrm{y}} / \gamma_{\mathrm{M} 0}$ [43] to account for the partial plastification, where $W_{\mathrm{el}}$ and $W_{\mathrm{ep}}$ are the elastic and elasto-plastic section moduli respectively. For Class 4 CHS, the design moment resistance is equal to the effective moment resistance $M_{\text {eff,Rd }}=W_{\text {eff }} f_{\mathrm{y}} / \gamma_{\mathrm{M} 0}$, where $W_{\text {eff }}$ is the effective section modulus. 
For Class 1 and 2 CHS under combined compression plus bending, a nonlinear plastic interaction formula is used. For Class 3 CHS, a linear interaction formula between $N_{\mathrm{pl}, \mathrm{Rd}}$ and $M_{\mathrm{el}, \mathrm{Rd}}\left(\right.$ or $\left.M_{\mathrm{ep}, \mathrm{Rd}}\right)$ is employed, while for Class 4 CHS, a similar linear interaction formula but between the effective crosssection resistances $-N_{\text {eff,Rd }}$ and $M_{\text {eff,Rd, }}$, is adopted.

\subsection{American Specification - ANSI/AISC 360-16}

The current American Specification ANSI/AISC 360-16 [10] covers steels with nominal yield strengths up to $690 \mathrm{MPa}$ for plates [11] and $485 \mathrm{MPa}$ for structural hollow sections [12]. To account for the different susceptibility to local buckling, a similar cross-section classification concept to that used in EC3, but under isolated loading only, is adopted in ANSI/AISC 360-16 [10]. Cross-sections under axial compression are classified as either nonslender or slender, depending on whether the plastic resistance $N_{\mathrm{pl}}$ is attainable. For the case of bending, the cross-sections are classified into three categories: compact, noncompact and slender, corresponding to the Class 1, Class 3 and Class 4 cross-sections, respectively, in EC3. The codified slenderness limits for CHS are summarised in Table 10.

Two design routes are provided in ANSI/AISC 360-16 [10], i.e. Load and Resistance Factor Design (LRFD) and Allowable Strength Design (ASD); in the present study, only LRFD is considered. A summary of the AISC resistance functions for the design of CHS is given in Table 12. Note that the AISC notation has been adjusted herein to be consistent with the EC3 notation system for comparison purposes. The resistance factor $\phi$ is adopted to account for unavoidable deviations of the nominal strength from the actual strength [10]; the resistance factors for compression and bending $-\phi_{\mathrm{c}}$ and $\phi_{\mathrm{b}}$, are both taken equal to 0.9 .

For CHS in axial compression, the cross-section design strength $N_{\mathrm{c}, \mathrm{Rd}}$ is equal to $N_{\mathrm{pl}, \mathrm{Rd}}$ and $N_{\mathrm{eff}, \mathrm{Rd}}$ for nonslender and slender CHS respectively, with a different equation for $A_{\text {eff }}$ from that used in EC3. For the case of bending, a three-stage design curve for compact, noncompact and slender CHS is employed. For CHS under combined compression plus bending, a bilinear interaction curve, which is the same as that for beam-column member design but anchored to the cross-section resistances under the 
compression and bending in isolation (i.e. $N_{\mathrm{c}, \mathrm{Rd}}$ and $M_{\mathrm{c}, \mathrm{Rd}}$ ), is employed, regardless of the local slenderness.

\section{Assessment of codified design provisions for CHS}

\subsection{General}

The accuracy and suitability of the codified cross-section design provisions for steel CHS in prEN 19931-1:2018 [25] and ANSI/AISC 360-16 [10] are assessed in this section. The test and numerical results generated from the present study, along with the existing test data collected from the literature, as reported by [43], are utilised herein. The suitability of the EC3 and AISC local slenderness limits is initially evaluated and discussed. The accuracy of the resistance functions is subsequently assessed through comparisons of the test and numerical data with the predicted resistances. Note that the comparisons are made based on the unfactored resistance predictions and assuming proportional loading.

\subsection{Local slenderness limits}

The slenderness limits for CHS set out in the upcoming version of EC3, prEN 1993-1-1:2018 [25], are firstly considered herein. To assess the slenderness limit for compression, the test and FE data are normalised by $N_{\mathrm{pl}}$ and plotted along with the codified resistance curves and slenderness limits in Fig. 26, where the Class 3 limit for compression appears to be on the safe side despite the relatively large scatter in the experimental data points.

The suitability of the slenderness limits for CHS in bending is analysed next. The assessment of the Class 1 limit is carried out using the rotation capacity data collected from the literature by [43], as plotted in Fig. 27. Upon initial inspection, there exists significant scatter in the rotation capacity data points; this is attributed to: (a) the inherent scattered nature of rotation capacity data, being associated with a horizontal measure on a relatively flat moment-deformation curve, (b) the sensitivity of the rotation capacity of CHS to initial local imperfections, (c) the different responses under uniform 
moment and moment gradients and (d) in some cases, the termination of testing before the applied moment descended back to $M_{\mathrm{pl}}$. A minimum rotation capacity of 3 was required for Class 1 crosssections in the development of EN 1993-1-1 [50]; it is clearly shown in Fig. 27 that the current Class 1 limit is safe-sided with some scope for relaxation. The Class 2 and 3 limits for bending, together with the bending test and FE data and the codified design curves, are plotted in Fig. 28 in a normalised manner. Note that only uniform bending test data representing the lower bound of the cross-sectional bending capacity have been included in the presented comparisons. Based on the numerical results, the Class 2 limit appears to be suitable for hot-rolled CHS but slightly conservative for cold-formed CHS, while the Class 3 limit appears to be overly conservative for both hot-rolled and cold-formed CHS. The experimental data points, although displaying a similar trend to the FE data, exhibit a high level of scatter; this is due, in some cases, to either the peak moment not being reached, or to local failure under concentrated loading as a consequence of insufficient stiffening of the tested profiles.

Having examined the EC3 local slenderness limits, the slenderness limits specified in ANSI/AISC 36016 are now assessed. The nonslender/slender limit for CHS in axial compression is plotted in Fig. 26; the AISC limit is slightly higher than the equivalent EC3 Class 3 limit for compression, but still appears to be on the safe side. For the case of bending, the compact/noncompact limit and the yield limit (i.e. $D / t \varepsilon^{2}=294.9$ or $D / t=0.33 E / f_{\mathrm{y}}$, corresponding to the first yield moment $\left.M_{\mathrm{el}}\right)$ are shown in Fig. 28. The compact/noncompact limit is slightly lower than the corresponding EC3 Class 2 limit and is shown to be appropriate despite the scatter in the test data. The AISC yield limit, which is considerably higher than its EC3 counterpart and even beyond the scope of prEN 1993-1-1:2018 [25], is shown to be more accurate than EC3 and to remain safe-sided, though the available test results are rather scarce in this range and further experiments are required to support this finding.

\subsection{Design functions}

In this subsection, the design predictions from EC3 and AISC, $R_{\mathrm{u}, \mathrm{EC} 3}$ and $R_{\mathrm{u}, \mathrm{AISC}}$ respectively, as defined in Fig. 29, are compared with the cross-section resistances derived from the tests and numerical simulations $R_{\mathrm{u}}$ (as illustrated Fig. 29) to evaluate the accuracy of the corresponding codified design 
functions. For the case of axial compression, the experimental and numerical results are normalised by the predicted resistances (where $R$ is equivalent to $N$ in this case) and plotted against the local slenderness $D / t \varepsilon^{2}$ in Fig. 30, with the statistical results summarised in Tables 13 and 14 for EC3 and AISC respectively. Close alignment of the data for normal and high strength steel CHS in compression can be observed upon initial inspection. For very stocky CHS, the predictions from both EC3 and AISC are shown to be overly conservative due to the neglect of the benefits from strain hardening, while for slender CHS, both design codes yield overly conservative resistance predictions, with a higher degree of conservatism in the predicted resistances from EC3 than from AISC.

For the case of bending, the test and FE moment resistances $M_{\mathrm{u}}$ are normalised by the predicted moment capacities (where $R$ is equivalent to $M$ in this case) and plotted against the local slenderness $D / t \varepsilon^{2}$ in Fig. 31; the corresponding statistical results are shown in Tables 13 and 14. Note that for EC3, the elasto-plastic design approach for Class 3 sections [43] has been implemented and assessed. Similar to compression, the data for both normal and high strength steel CHS in bending are closely aligned. A fairly high level of conservatism for both EC3 and AISC is again observed in the very stocky range due to the lack of account of strain hardening. The EC3 design functions are rather conservative in the Class 3 and 4 ranges due primarily to the overly strict Class 3 limit and consequently the somewhat conservative predictive formula for the effective section modulus. The AISC design functions, on the other hand, generally provide accurate yet safe-sided resistance predictions for compact and noncompact $\mathrm{CHS}$, while in the slender range, an increasing level of conservatism with increasing local slenderness is revealed.

For combined loading, the test and FE data are normalised by the predicted cross-section capacities under compression and bending in isolation (denoted by $N_{\mathrm{c}, \mathrm{EC} 3}$ and $M_{\mathrm{c}, \mathrm{EC} 3}$ for EC3 and $N_{\mathrm{c}, \mathrm{AISC}}$ and $M_{\mathrm{c}, \mathrm{AISC}}$ for AISC) and plotted in Figs. 32 and 33 for EC3 and AISC respectively. The accuracy of both design codes is also presented quantitatively by the statistical results given in Tables 13 and 14. Again, the data points for normal and high strength steel CHS are shown to follow the same trend in general. Owing to the neglect of strain hardening, both codified design methods are overly conservative in the stocky range. 
Compared with the AISC bilinear interaction curve, the EC3 nonlinear interaction curve for Class 1 and 2 CHS more accurately captures the fully plastic response of CHS under combined loading. For Class 3 and 4 CHS, the EC3 linear interaction curve is tied to the unduly conservative cross-section resistance predictions under isolated loading, therefore leading to rather conservative and scattered predictions under combined loading. The resistance predictions from AISC, on the other hand, follow a tighter trend due to the adoption of more accurate end points for the interaction curve.

\section{Conclusions}

A comprehensive experimental and numerical study into the cross-sectional behaviour of structural steel circular hollow sections (CHS) under compression, bending and combined compression plus bending has been conducted. Six cold-formed S700 CHS were tested, covering Class 1 to 4 in compression according to EN 1993-1-1. In total, twelve tensile coupon tests, a series of local imperfection measurements, six stub column tests, six four-point bending tests, six three-point bending tests and fifteen short beam-column tests were conducted. In conjunction with the experimental programme, finite element models were established, validated against the obtained test results and then utilised for parametric studies, where over 1650 additional cross-sectional resistance data on CHS were numerically derived. The obtained experimental and numerical results were combined with existing cross-section test data from the literature and utilised for the assessment of the cross-section design provisions for CHS in Eurocode 3 (prEN 1993-1-1:2018) and the American Specification ANSI/AISC 360-16. Both EC3 and AISC were shown to underestimate the cross-section capacity of stocky CHS due to the neglect of strain hardening. For EC3, it was further revealed that the Class 3 limits and the design equations for effective area and effective section modulus for CHS are somewhat conservative. This also affects the accuracy of the EC3 predictions for combined loading due to the adoption of the resistances under isolated loading as the end points for the interaction curves. 


\section{Acknowledgements}

The present study was part of the project HOLLOSSTAB funded by the Research Fund for Coal and Steel (RFCS) under Grant Agreement No. 709892 (2016). The authors would like to acknowledge SSAB for the supply of test materials and Trevor Stickland, Gordon Herbert and Alfredo Olivo for their assistance during the experiments. The authors also gratefully acknowledge the Skempton Scholarship from Imperial College London for the financial support. 


\section{References}

[1] N. Baddoo, Editorial, Proc. Inst. Civ. Eng. Struct. Build. 170 (9) (2017) 619-620.

[2] Chenfu, 2008 Summer Olympics flame at Beijing National Stadium [Image], 2008. Available from: http://cc.nphoto.net/view/2008/10327.shtml.

[3] N. Janberg, Nesenbach Valley Bridge (Image-ID: 2260) [Image], 2002. Available from: https://structurae.net/en/photos/2260-nesenbach-valley-bridge.

[4] International Association for Bridge and Structural Engineering, Use and Application of HighPerformance Steels for Steel Structures, International Association for Bridge and Structural Engineering (IABSE), 2005.

[5] EN 10210-2:2006, Hot finished structural hollow sections of non-alloy and fine grain steels — Part

2: Tolerances, dimensions and sectional properties, European Committee for Standardization (CEN), Brussels, 2006.

[6] EN 10219-2:2006, Cold formed welded structural hollow sections of non-alloy and fine grain steels

— Part 2: Tolerances, dimensions and sectional properties, European Committee for Standardization (CEN), Brussels, 2006.

[7] EN 1993-1-1:2005, Eurocode 3: design of steel structures - Part 1-1: General rules and rules for buildings, European Committee for Standardization (CEN), Brussels, 2005.

[8] EN 1993-1-12:2007, Eurocode 3 - Design of steel structures - Part 1-12: Additional rules for the extension of EN 1993 up to steel grades S 700, European Committee for Standardization (CEN), Brussels, 2007.

[9] GB 50017-2017, Standard for design of steel structures, Ministry of Housing and Urban-Rural Development of the People's Republic of China (MOHURD), Beijing, 2017.

[10] ANSI/AISC 360-16, Specification for structural steel buildings, American Institute of Steel Construction (AISC), Chicago, 2016.

[11] A514/A514M - 18e1, Standard specification for high-yield-strength, quenched and tempered alloy steel plate, suitable for welding, American Society for Testing and Materials (ASTM). West Conshohocken, 2018. 
[12] A1085/A1085M - 15, Standard specification for cold-formed welded carbon steel hollow structural sections (HSS), American Society for Testing and Materials (ASTM). West Conshohocken, 2015.

[13] AS 4100-1998 Rec:2016, Steel structures, Standards Australia, Sydney, 2016.

[14] H. Jiao, X.L. Zhao, Section slenderness limits of very high strength circular steel tubes in bending, Thin-Walled Struct. 42 (9) (2004) 1257-1271.

[15] J.L. Ma, T.M. Chan, B. Young, Experimental investigation on stub-column behavior of coldformed high-strength steel tubular sections, J. Struct. Eng. 142 (5) (2016) 04015174.

[16] J. Wang, S. Afshan, N. Schillo, M. Theofanous, M. Feldmann, L. Gardner, Material properties and compressive local buckling response of high strength steel square and rectangular hollow sections, Eng. Struct. 130 (2017) 297-315.

[17] X. Meng, L. Gardner, Testing of hot-finished high strength steel SHS and RHS under combined compression and bending, Thin-Walled Struct. (2019) 106262.

[18] K.J.R. Rasmussen, G.J. Hancock, G. J. Plate slenderness limits for high strength steel sections, J. Constr. Steel Res. 23 (1) (1992) 73-96.

[19] N. Schillo, M. Feldmann, Local buckling behaviour of welded box sections made of high-strength steel, Steel Construction 8 (3) (2015) 179-186.

[20] H. Fang, T.M. Chan, B. Young, Behavior of octagonal high-strength steel tubular stub columns, J. Struct. Eng. 145 (12) (2019) 04019150.

[21] H, Ban, G. Shi, Y. Shi, M.A. Bradford, Experimental investigation of the overall buckling behaviour of $960 \mathrm{MPa}$ high strength steel columns, J. Constr. Steel Res. 88 (2013) 256-266.

[22] A.E. Pournara, S.A. Karamanos, E. Mecozzi, A. Lucci, Structural resistance of high-strength steel CHS members, J. Constr. Steel Res. 128 (2017) 152-165.

[23] B. Somodi, B. Kövesdi, Residual stress measurements on cold-formed HSS hollow section columns, J. Constr. Steel Res. 128 (2017) 706-720.

[24] J. Wang, L. Gardner, Flexural buckling of hot-finished high-strength steel SHS and RHS columns, J. Struct. Eng. 143 (6) (2017) 04017028.

[25] prEN 1993-1-1:2018, Eurocode 3: design of steel structures - Part 1-1: General rules and rules for buildings, European Committee for Standardization (CEN), Brussels, 2018. Final document. 
[26] EN 10149-1:2013, Hot rolled flat products made of high yield strength steels for cold forming Part 1: General technical delivery conditions, European Committee for Standardization (CEN), Brussels, 2013.

[27] T.M. Chan, L. Gardner, Bending strength of hot-rolled elliptical hollow sections, J. Constr. Steel Res. 64 (9) (2008) 971-986.

[28] T.M. Chan, L. Gardner, K.H. Law, Structural design of elliptical hollow sections: a review, Proc. Inst. Civ. Eng. Struct. Build. 163 (6) (2010) 391-402.

[29] EN ISO 6892-1:2016, Metallic materials - Tensile testing Part 1: Method of test at room temperature, European Committee for Standardization (CEN), Brussels, 2016.

[30] Bluehill 2, Instron, 2008.

[31] B.W. Schafer, T. Peköz, Computational modeling of cold-formed steel: Characterizing geometric imperfections and residual stresses, J. Constr. Steel Res. 47 (3) (1998) 193-210.

[32] L. Gardner, N. Saari, F. Wang, Comparative experimental study of hot-rolled and cold-formed rectangular hollow sections, Thin-Walled Struct. 48 (7) (2010) 495-507.

[33] O. Zhao, B. Rossi, L. Gardner, B. Young, Behaviour of structural stainless steel cross-sections under combined loading - Part I: Experimental study, Eng. Struct. 89 (2015) 236-246.

[34] R.D. Ziemian, Guide to Stability Design Criteria for Metal Structures, Sixth ed., New York, John Wiley \& Sons, Inc., 2010.

[35] Centre for Advanced Structural Engineering, Compression Tests of Stainless Steel Tubular Columns, Investigation Report S770, 1990.

[36] L. Gardner, A New Approach to Structural Stainless Steel Design, Ph.D. thesis, Imperial College London, 2002.

[37] L. Gardner, D.A. Nethercot, Experiments on stainless steel hollow sections-Part 1: Material and cross-sectional behaviour, J. Constr. Steel Res. 60 (9) (2004) 1291-1318.

[38] DaVis 10, LaVision, 2017.

[39] Abaqus 2016, SIMULIA - Dassault Systèmes, 2016.

[40] A. Espinos, L. Gardner, M.L. Romero, A. Hospitaler, Fire behaviour of concrete filled elliptical steel columns, Thin-Walled Struct. 49 (2011) 239-255. 
[41] A. Limam, L.H. Lee, E. Corona, S. Kyriakides, Inelastic wrinkling and collapse of tubes under combined bending and internal pressure, Int. J. Mech. Sci. 52 (5) (2010) 637-647.

[42] J.M. Rotter, A.J. Sadowski, L. Chen, Nonlinear stability of thin elastic cylinders of different length under global bending, Int. J. Solids Struct. 51 (15-16) (2014) 2826-2839.

[43] X. Meng, L. Gardner, A.J. Sadowski, J.M. Rotter, Elasto-plastic behaviour and design of semicompact circular hollow sections, Thin-Walled Struct. (2019) 106486.

[44] X. Meng, L. Gardner, Simulation and design of semi-compact elliptical hollow sections, Eng. Struct. $202(2020) 109807$.

[45] K.H. Law, L. Gardner, Lateral instability of elliptical hollow section beams, Eng. Struct. 37 (2012) $152-166$.

[46] J. Wang, S. Afshan, M. Gkantou, M. Theofanous, C. Baniotopoulos, L. Gardner, Flexural behaviour of hot-finished high strength steel square and rectangular hollow sections, J. Constr. Steel Res. 121 (2016) 97-109.

[47] F. Wang, O. Zhao, B. Young, Testing and numerical modelling of S960 ultra-high strength steel angle and channel section stub columns, Eng. Struct. 204 (2020) 109902.

[48] X. Yun, L. Gardner, Stress-strain curves for hot-rolled steels, J. Constr. Steel Res. 133 (2017) 3646.

[49] L. Gardner, X. Yun, Description of stress-strain curves for cold-formed steels, Constr. Build. Mater. 189 (2018) 527-538.

[50] L. Gardner, T.M. Chan, Cross-section classification of elliptical hollow sections, Steel Compos. Struct. 7 (3) (2007) 185-200. 

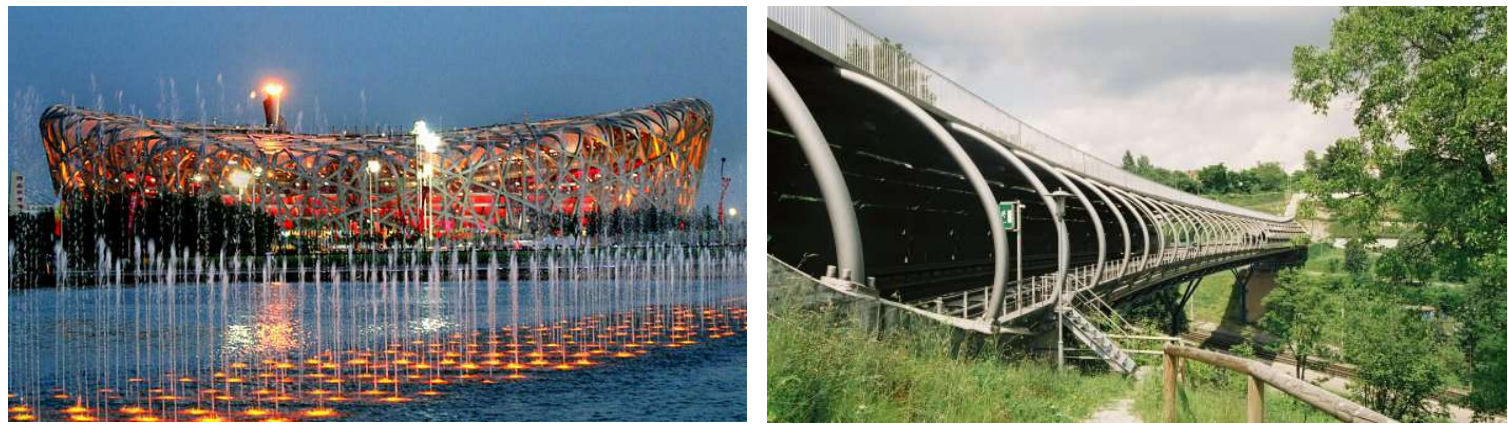

Fig. 1. National Stadium (the Bird's Nest) in Beijing (left) [2] and Nesenbach Valley Bridge in Stuttgart (right) [3]

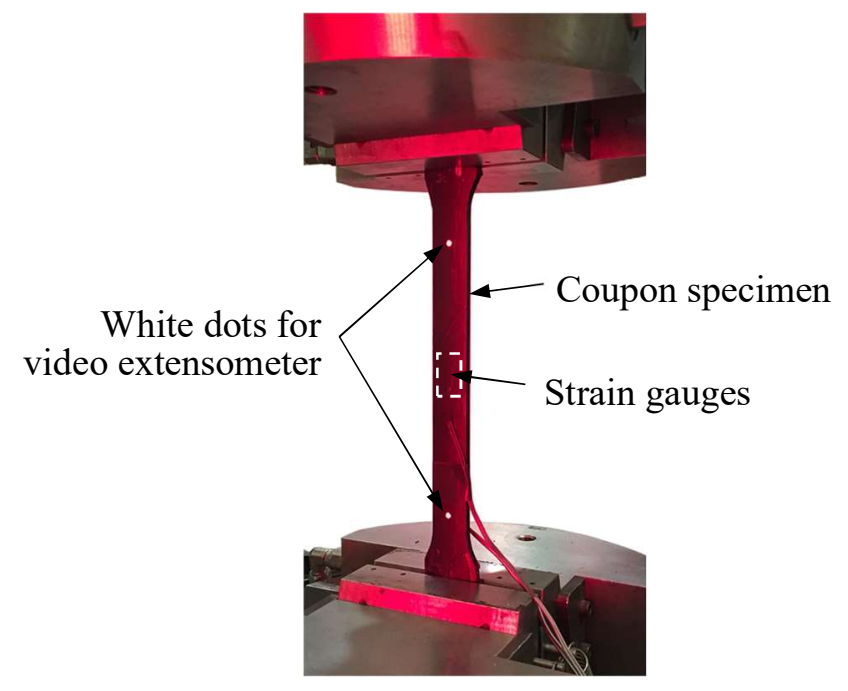

Fig. 2. Tensile coupon test setup

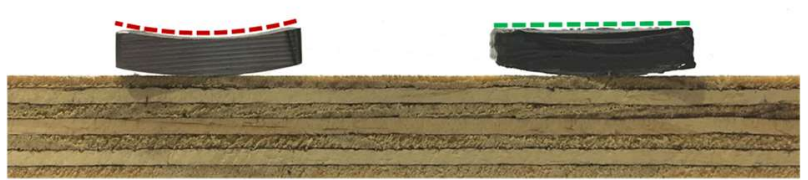

Fig. 3. Curved ends of coupon specimens: without epoxy putty (left) and with epoxy putty (right)

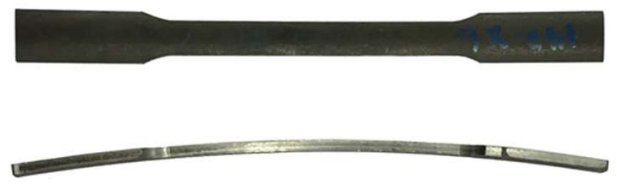

Fig. 4. Typical extracted coupon specimen (from CHS 139.7×6) 


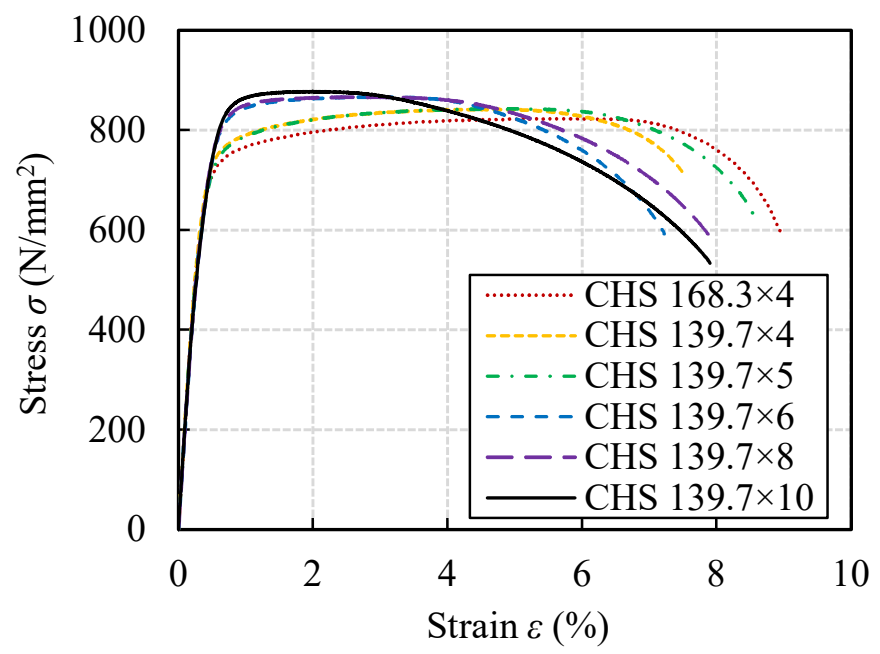

Fig. 5. Average engineering stress-strain curves from tensile coupon tests

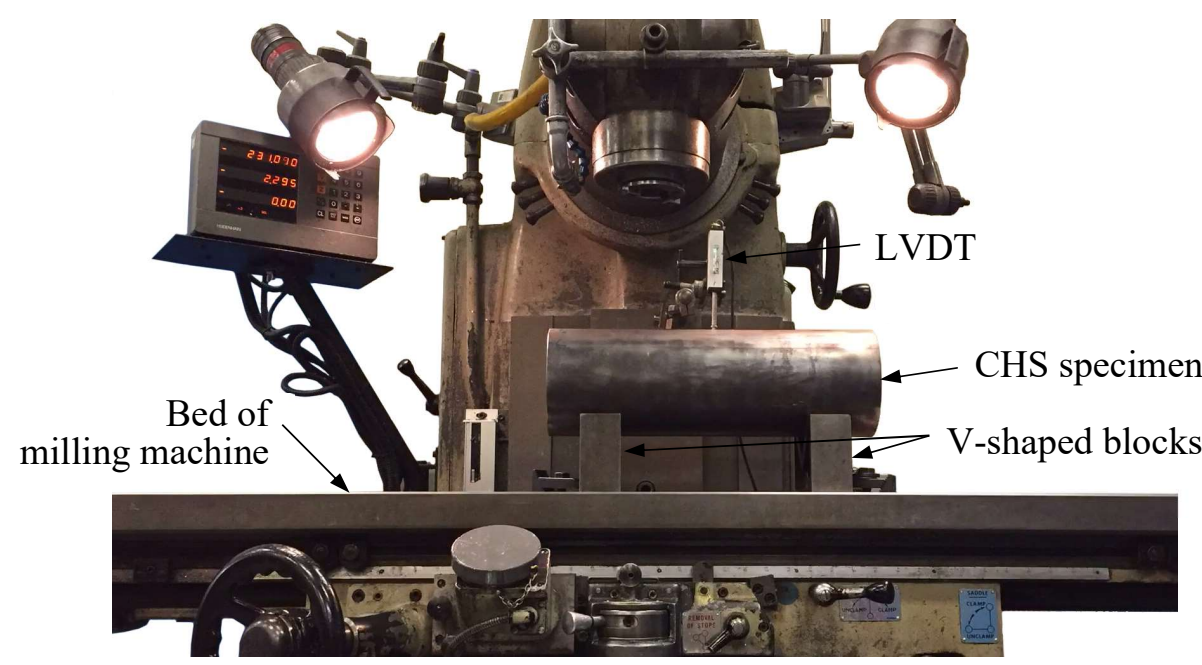

Fig. 6. Local geometric imperfection measurement setup

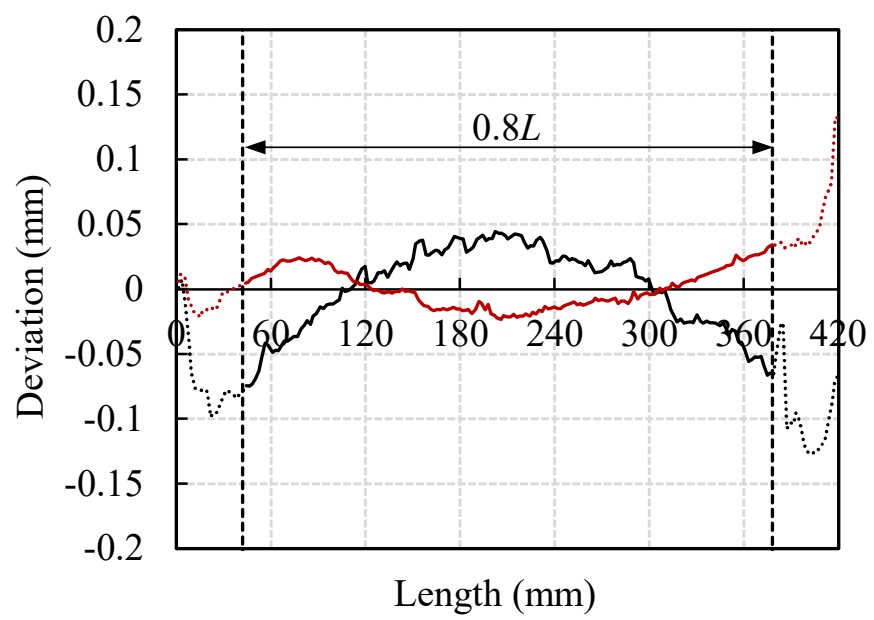

Fig. 7. Typical results from local geometric imperfection measurements 


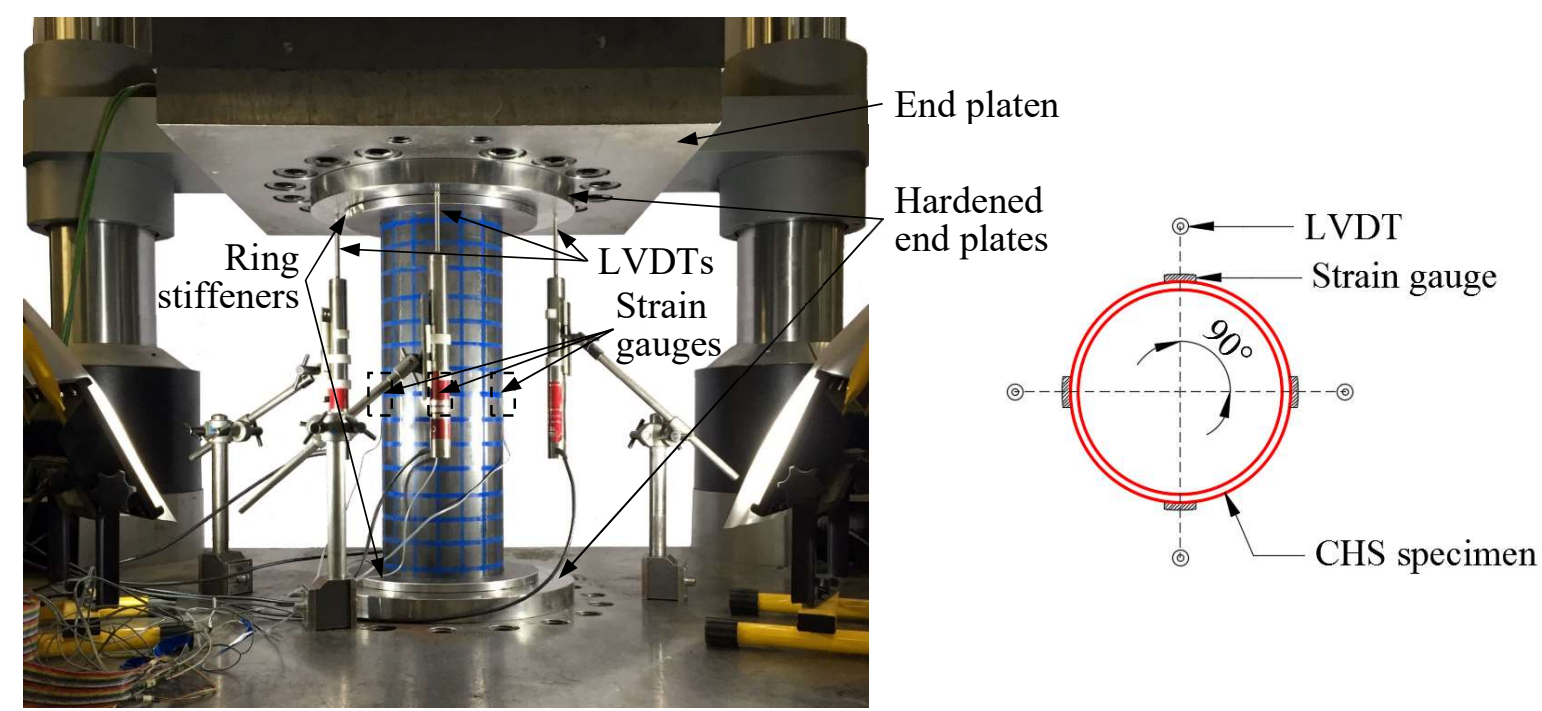

Fig. 8. Stub column test setup (left) and arrangement of strain gauges and LVDTs (right)

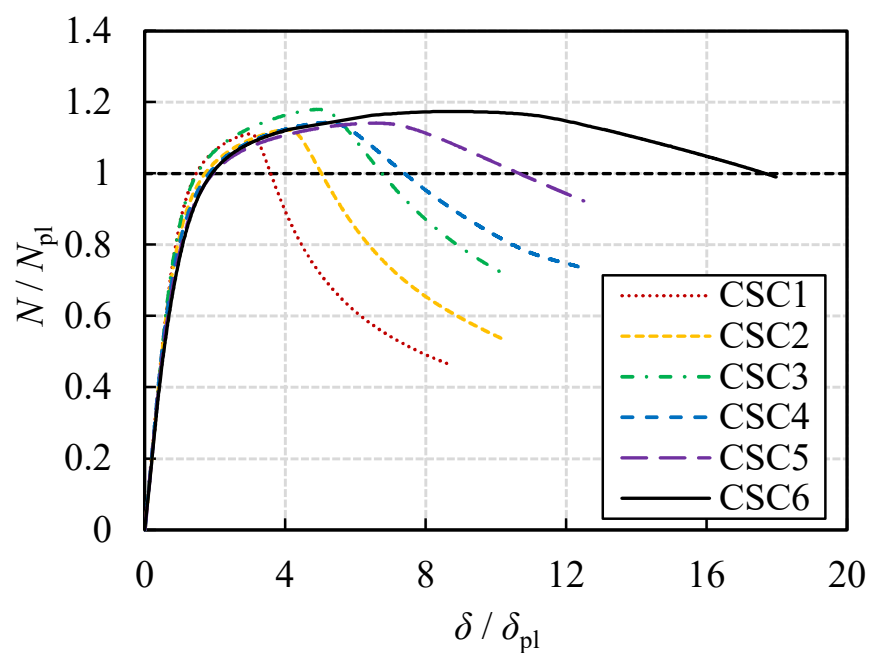

Fig. 9. Normalised load-end shortening curves from stub column tests

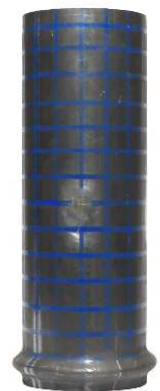

$\mathrm{CSC} 2$

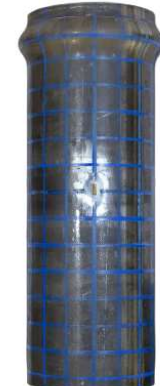

$\mathrm{CSC} 4$

CHS $139.7 \times 4$

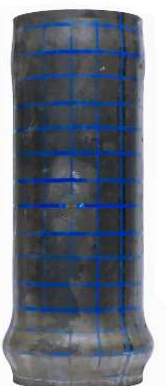

CSC6

CHS $139.7 \times 6 \quad$ CHS $139.7 \times 10$

Fig. 10. Typical failure modes of stub columns (scale in mm) 


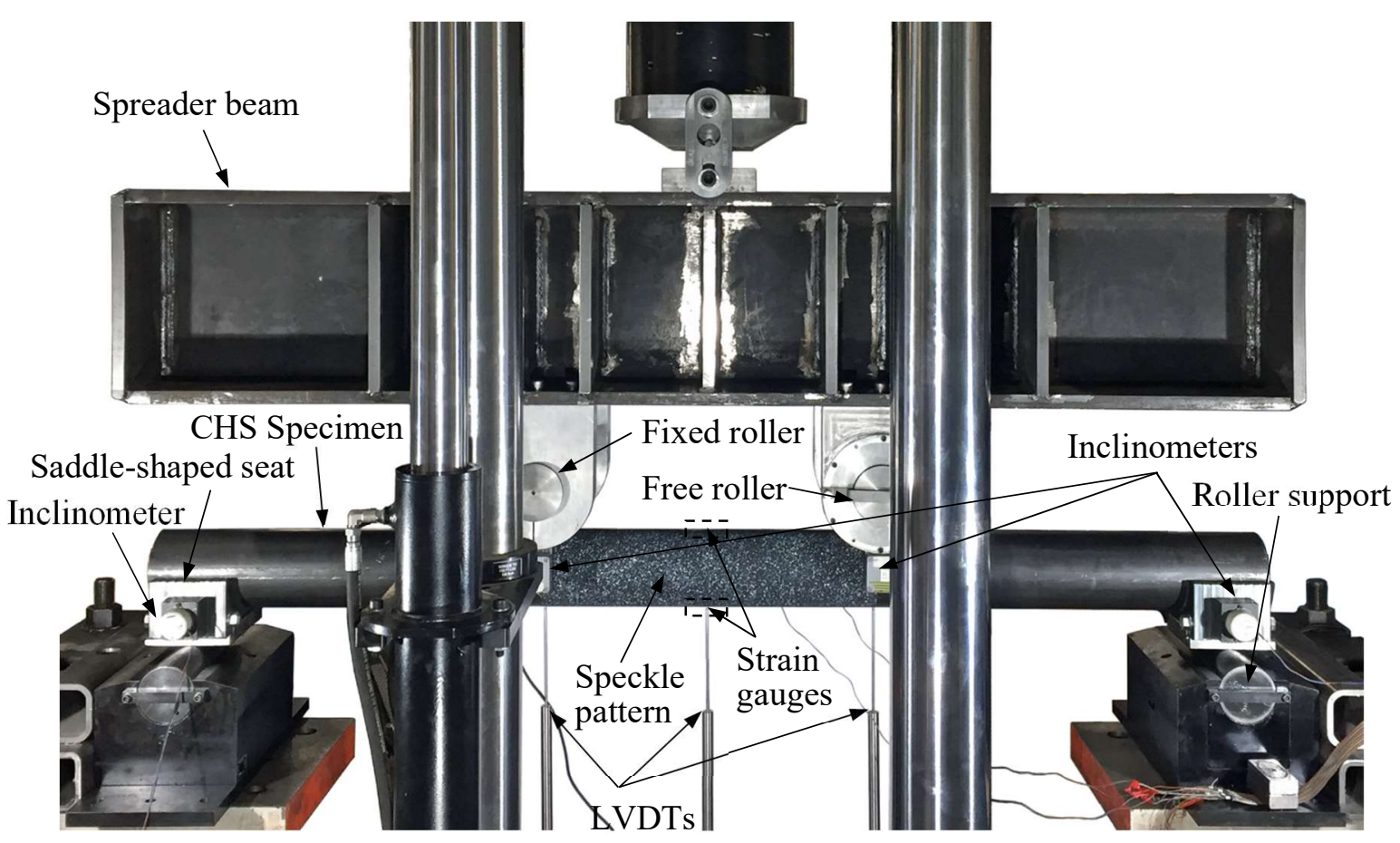

Fig. 11. Four-point bending test setup

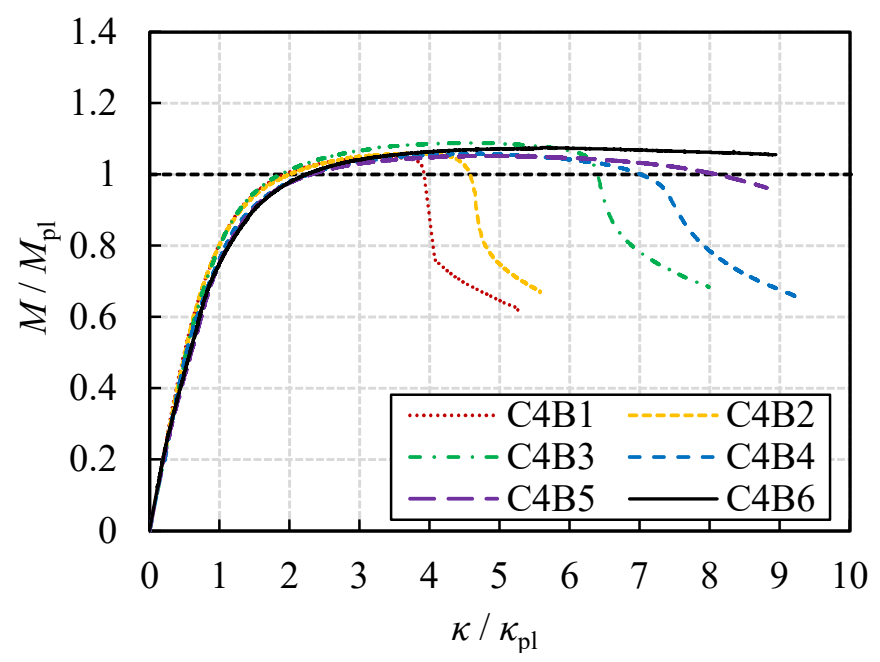

Fig. 12. Normalised moment-average curvature curves from four-point bending tests 


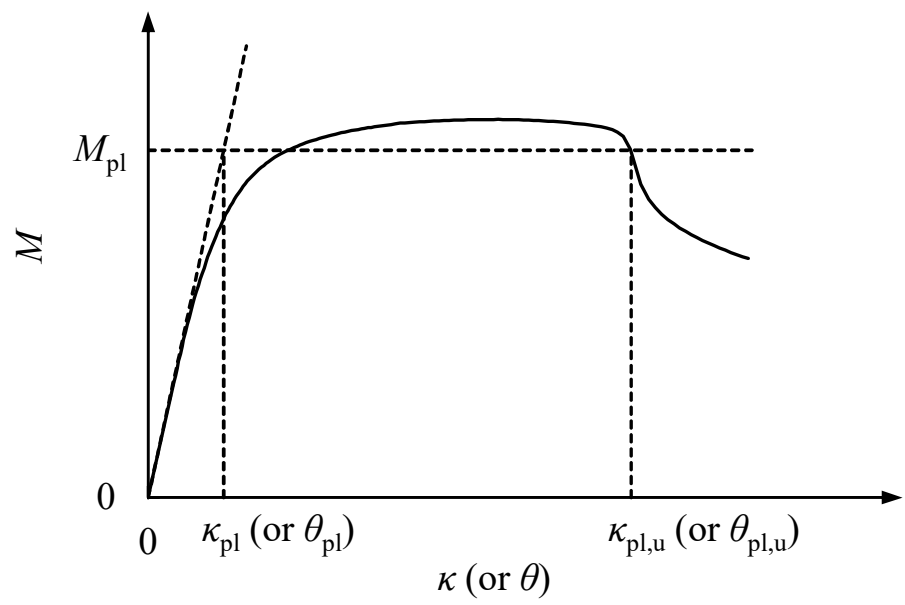

Fig. 13. Definition of parameters for calculation of rotation capacity $R$

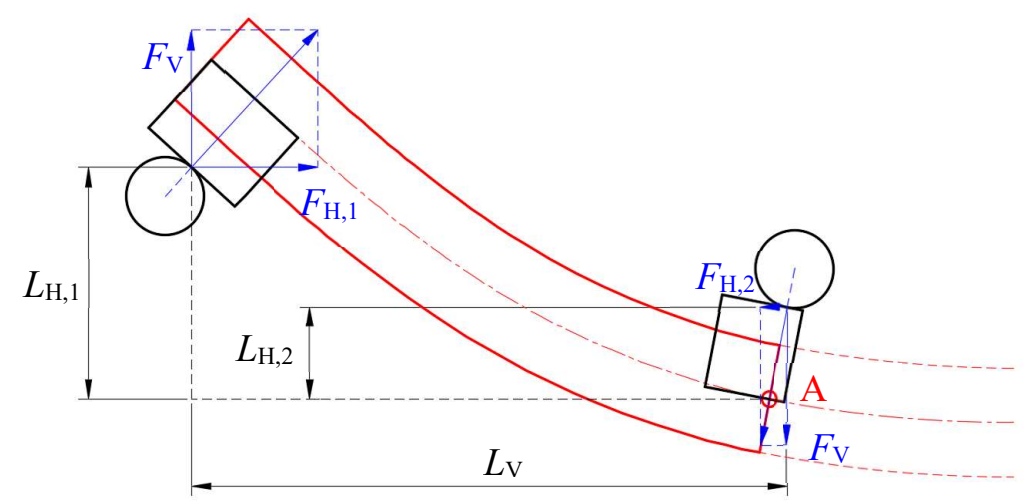

Fig. 14. Applied forces in shear span for four-point bending tests

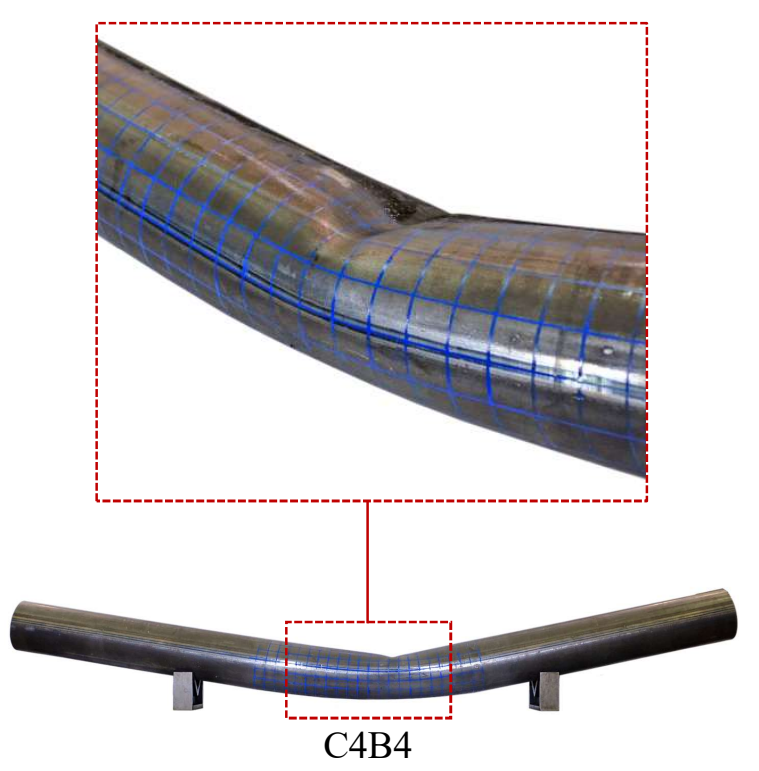

CHS $139.7 \times 6$

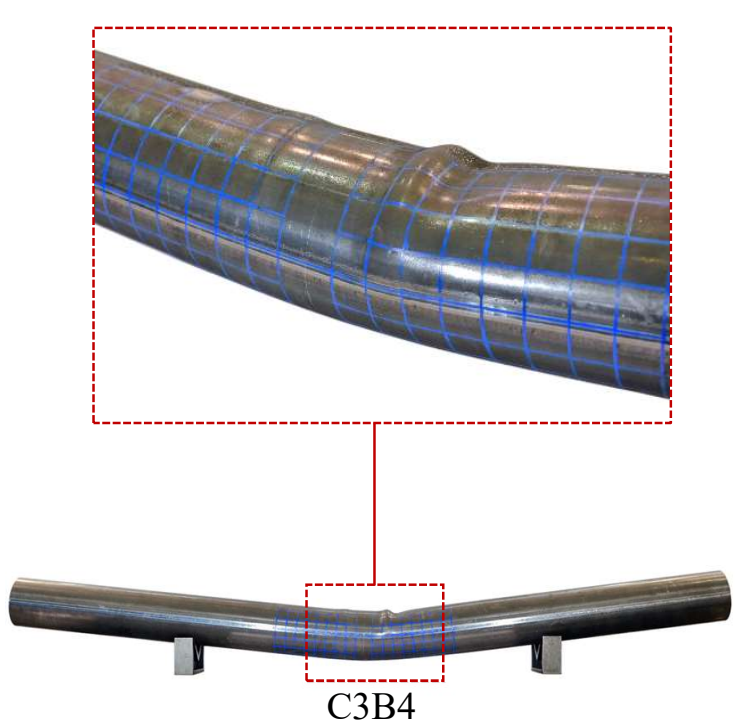

CHS $139.7 \times 6$

Fig. 15. Typical failure modes of beams under four-point bending (left) and three-point bending (right) $(\mathrm{CHS} 139.7 \times 6)$ 


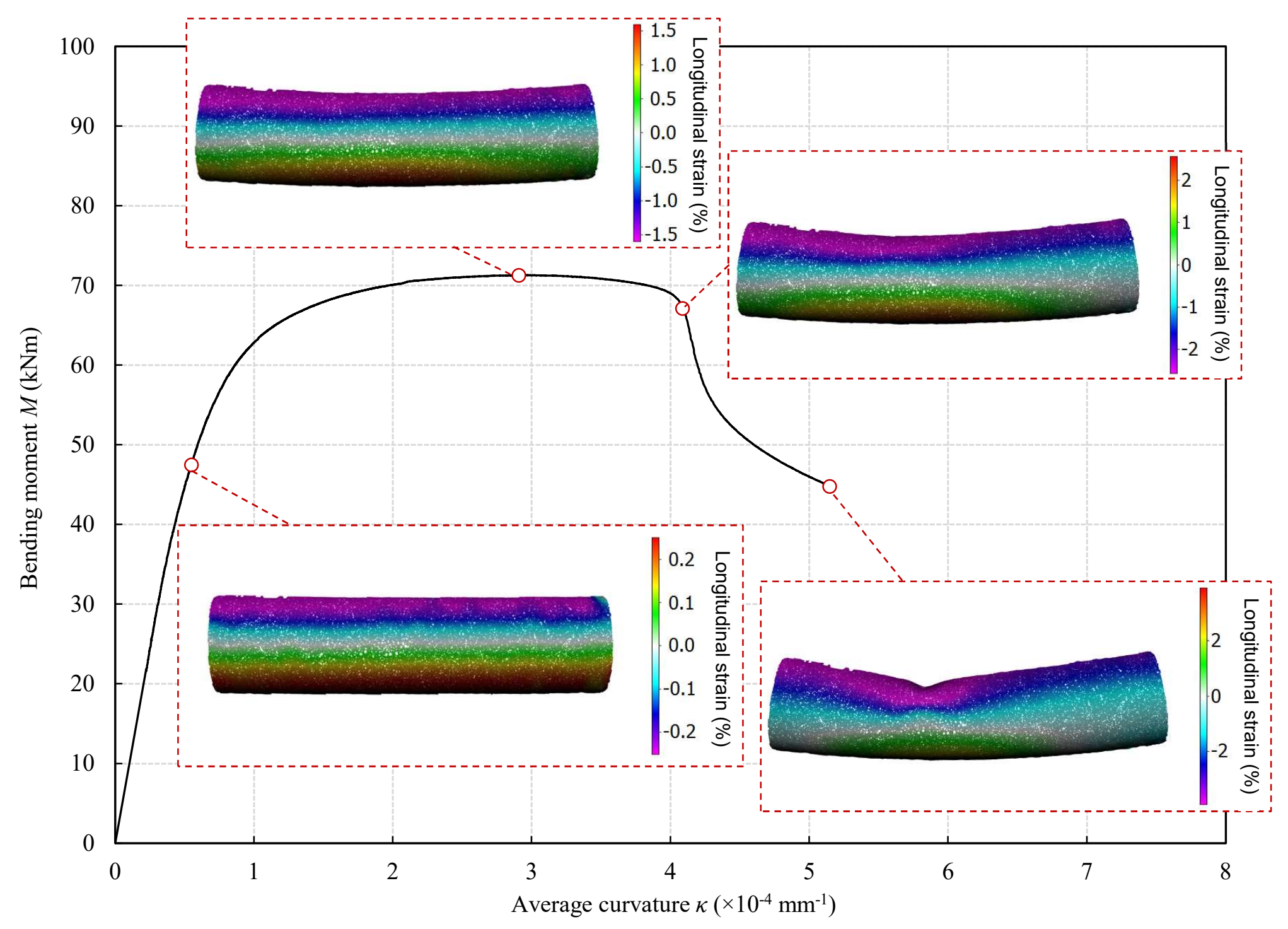

Fig. 16. Typical DIC results from four-point bending tests (C4B4, CHS 139.7×6) 


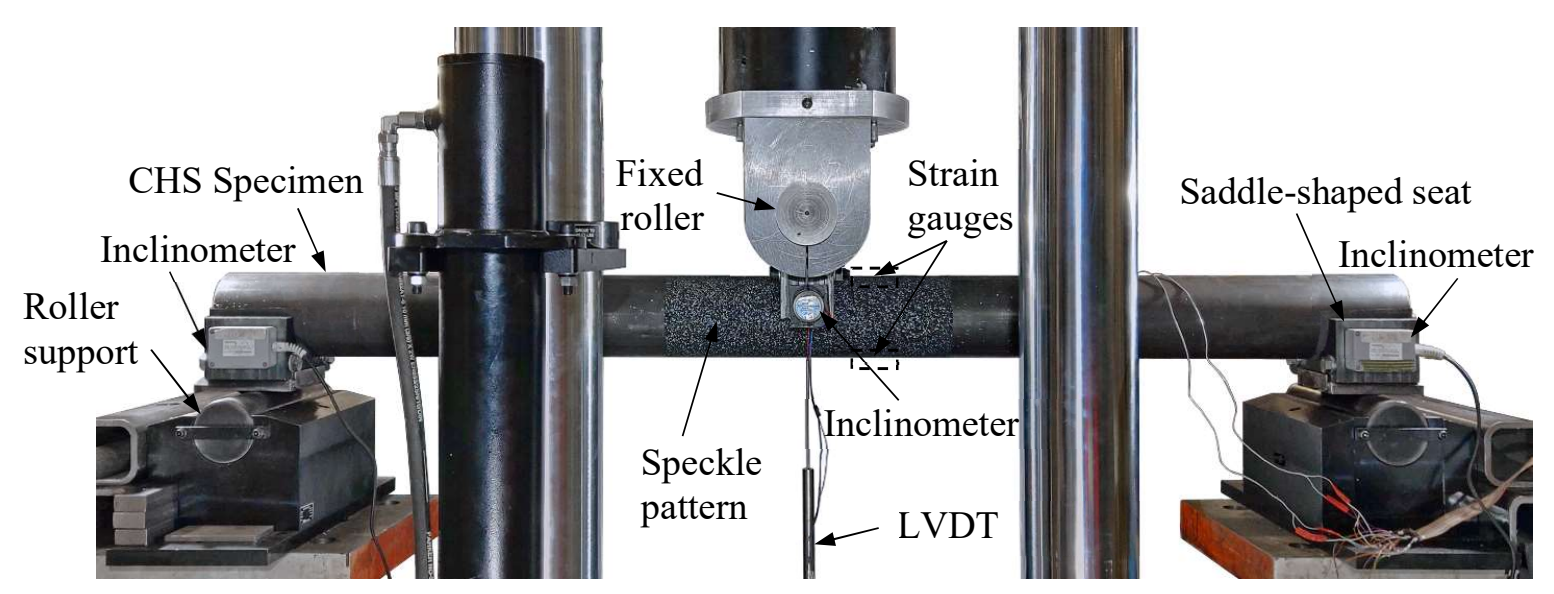

Fig. 17. Three-point bending test setup

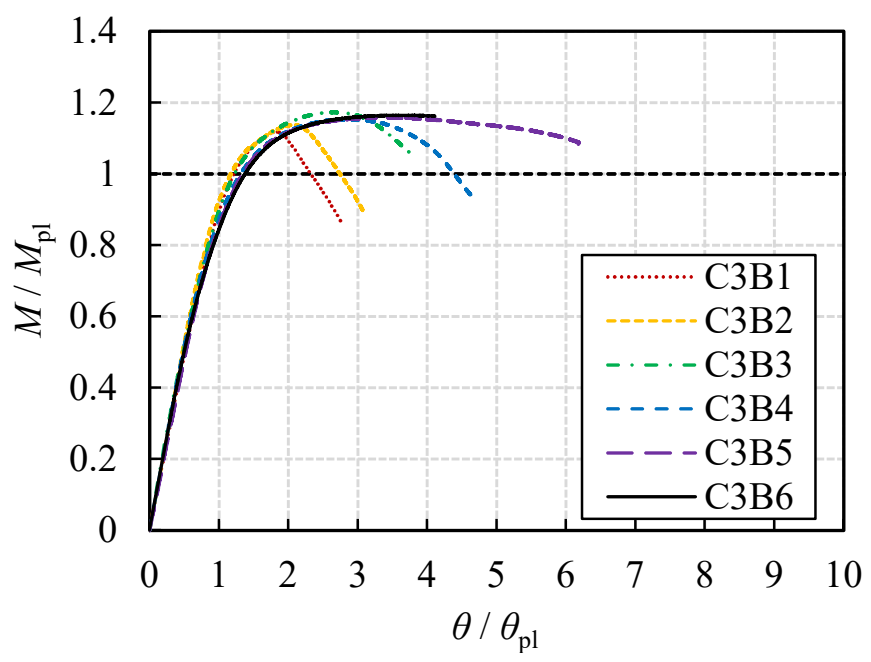

Fig. 18. Normalised moment-end rotation curves from three-point bending tests

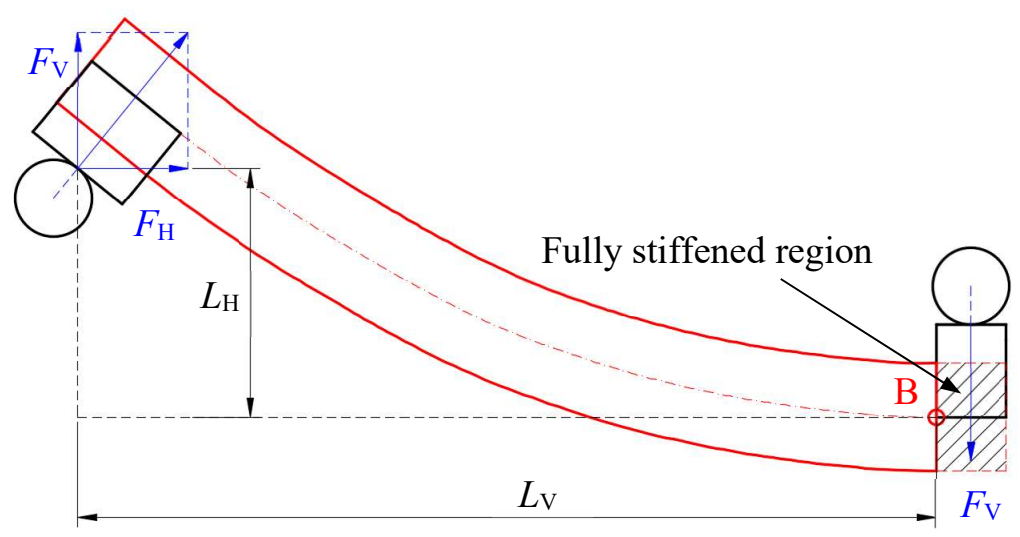

Fig. 19. Applied forces in shear span for three-point bending tests 


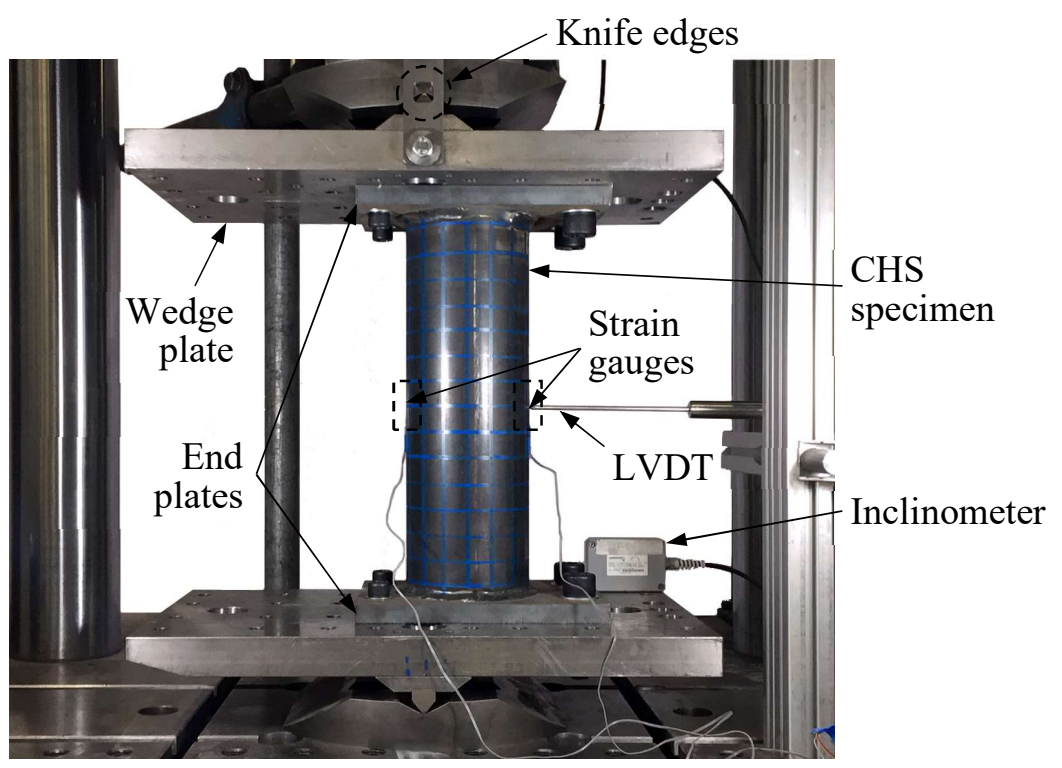

Fig. 20. Short beam-column test setup
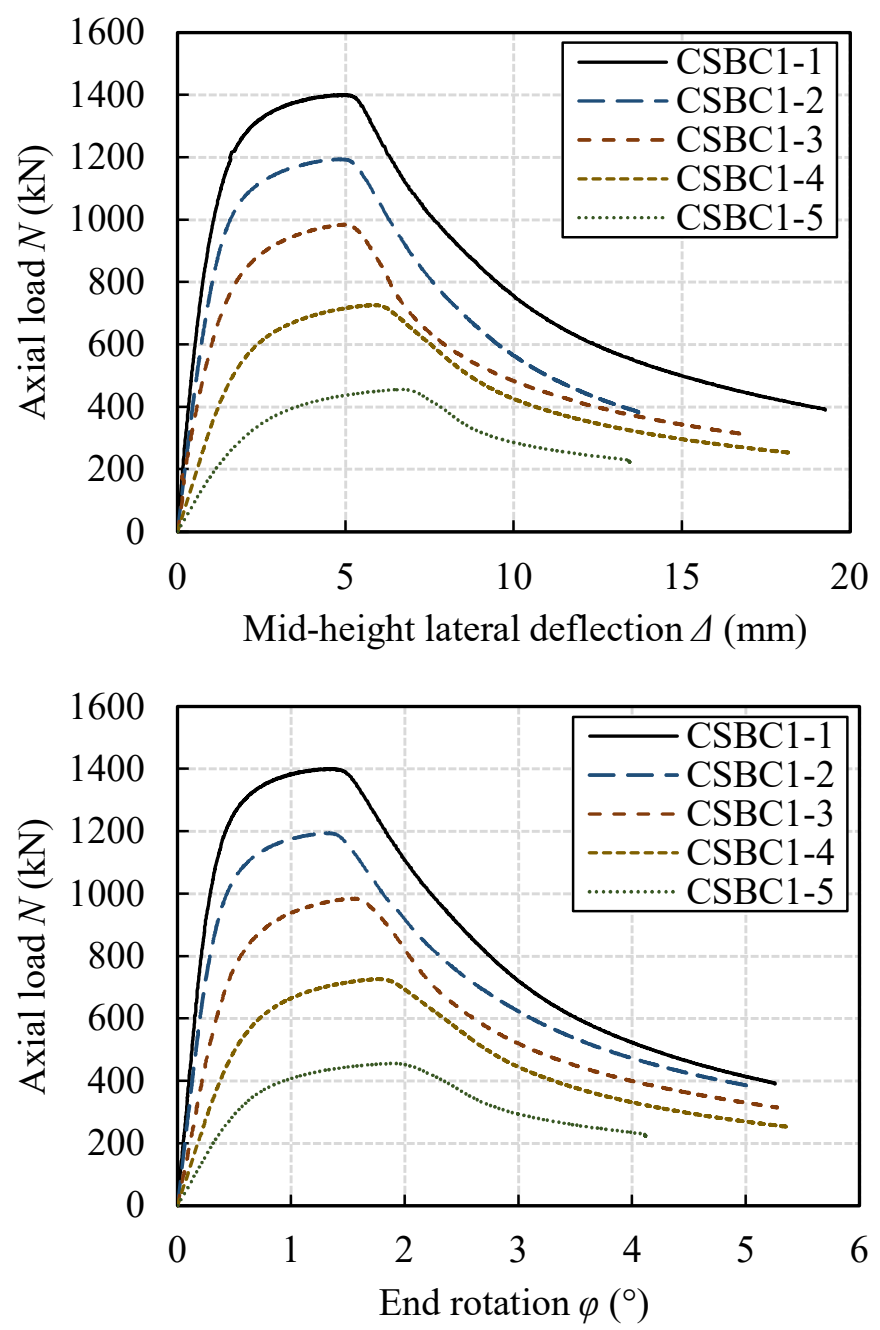

(a) CHS 168.3×4 (CSBC1 series) 

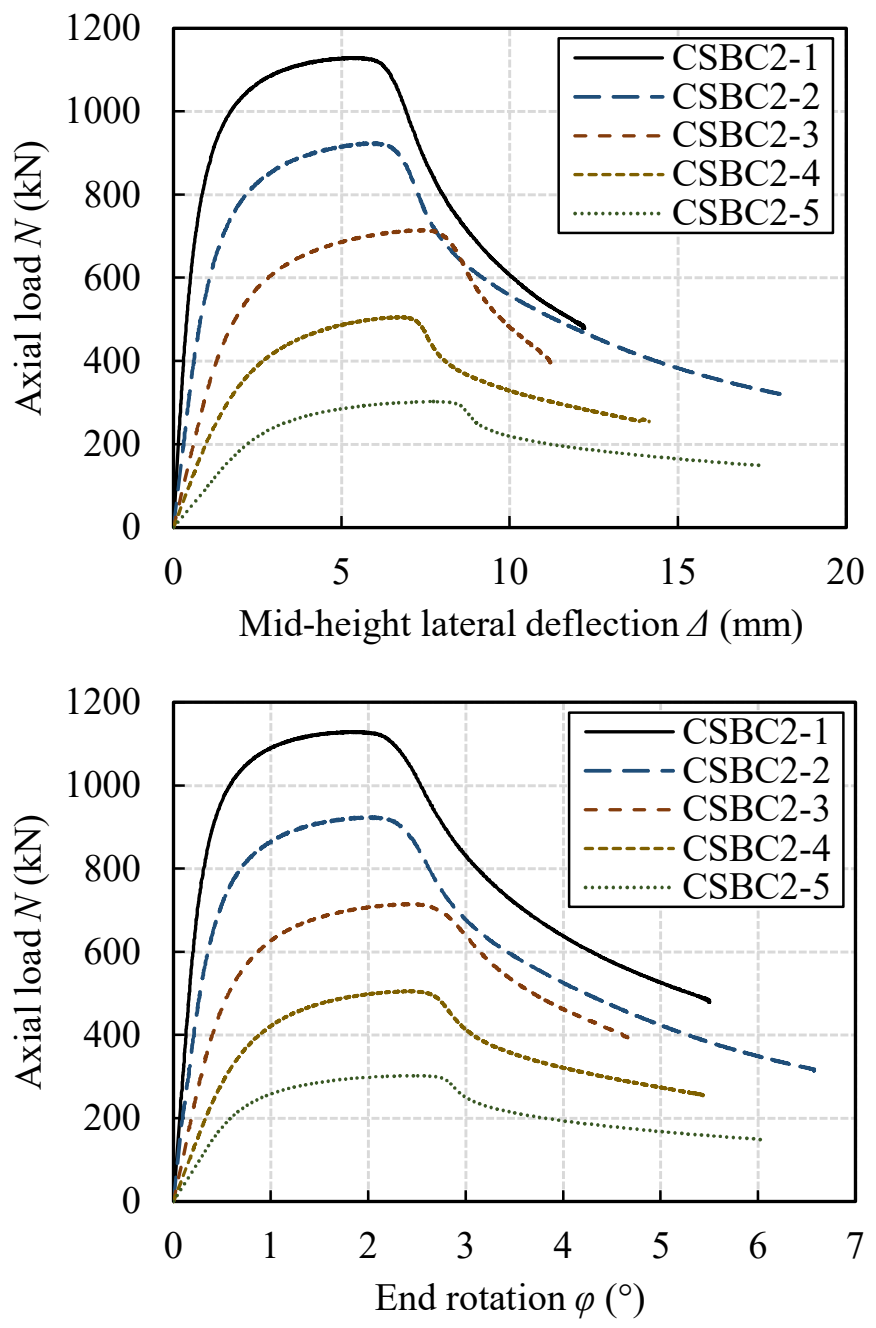

(b) CHS $139.7 \times 4$ (CSBC2 series) 

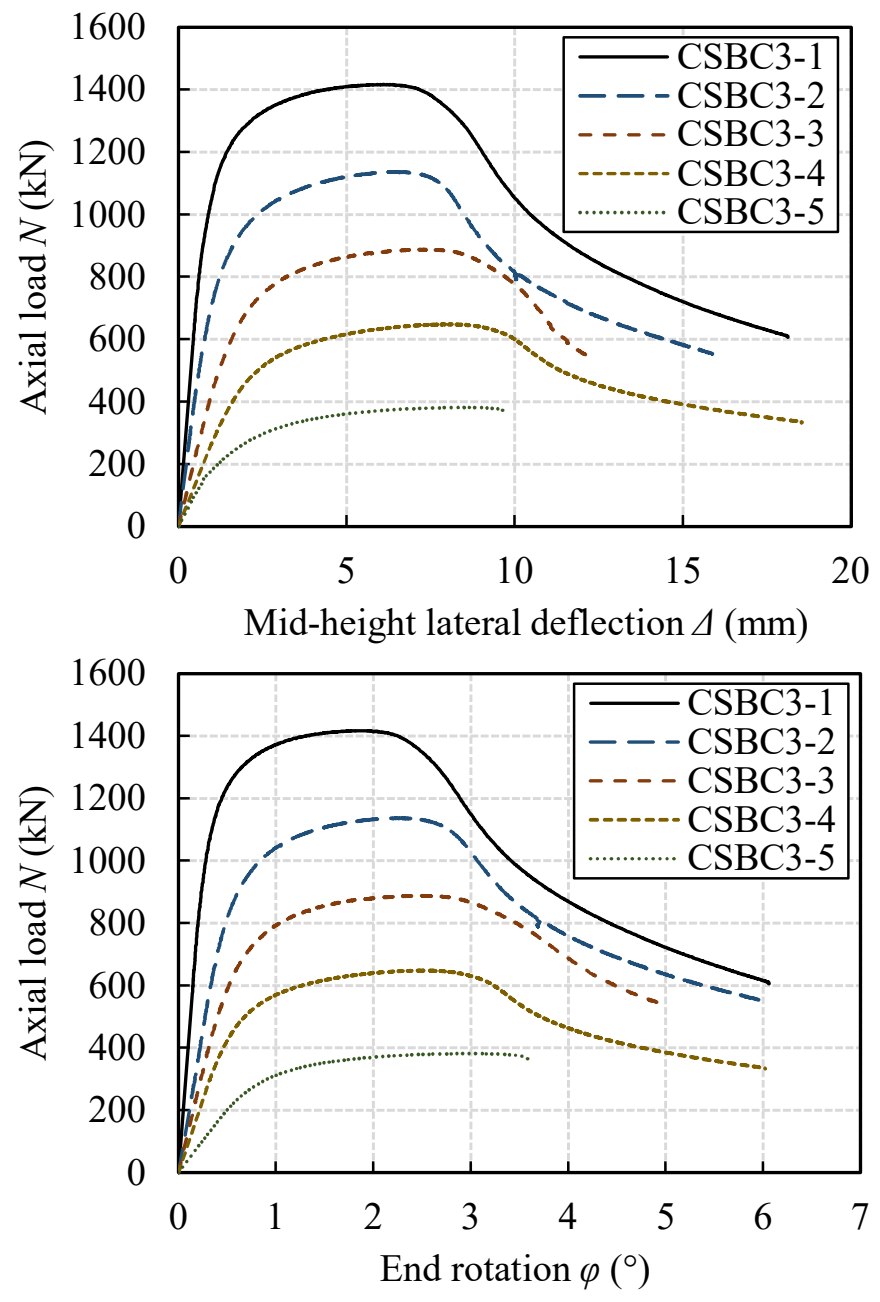

(c) CHS $139.7 \times 5$ (CSBC3 series)

Fig. 21. Load-deformation curves from short beam-column tests for (a) CHS $168.3 \times 4$ (CSBC1 series), (b) CHS $139.7 \times 4$ (CSBC2 series) and (c) CHS 139.7 ×5 (CSBC3 series)
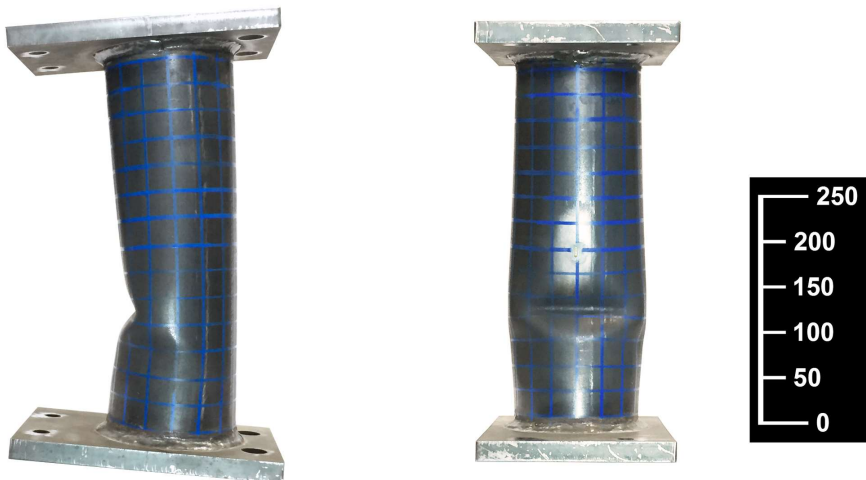

$\mathrm{CSC} 2-4$

CHS $139.7 \times 4, e_{\mathrm{n}}=85 \mathrm{~mm}$

Fig. 22. Typical failure mode of short beam-columns (scale in $\mathrm{mm}$ ) 


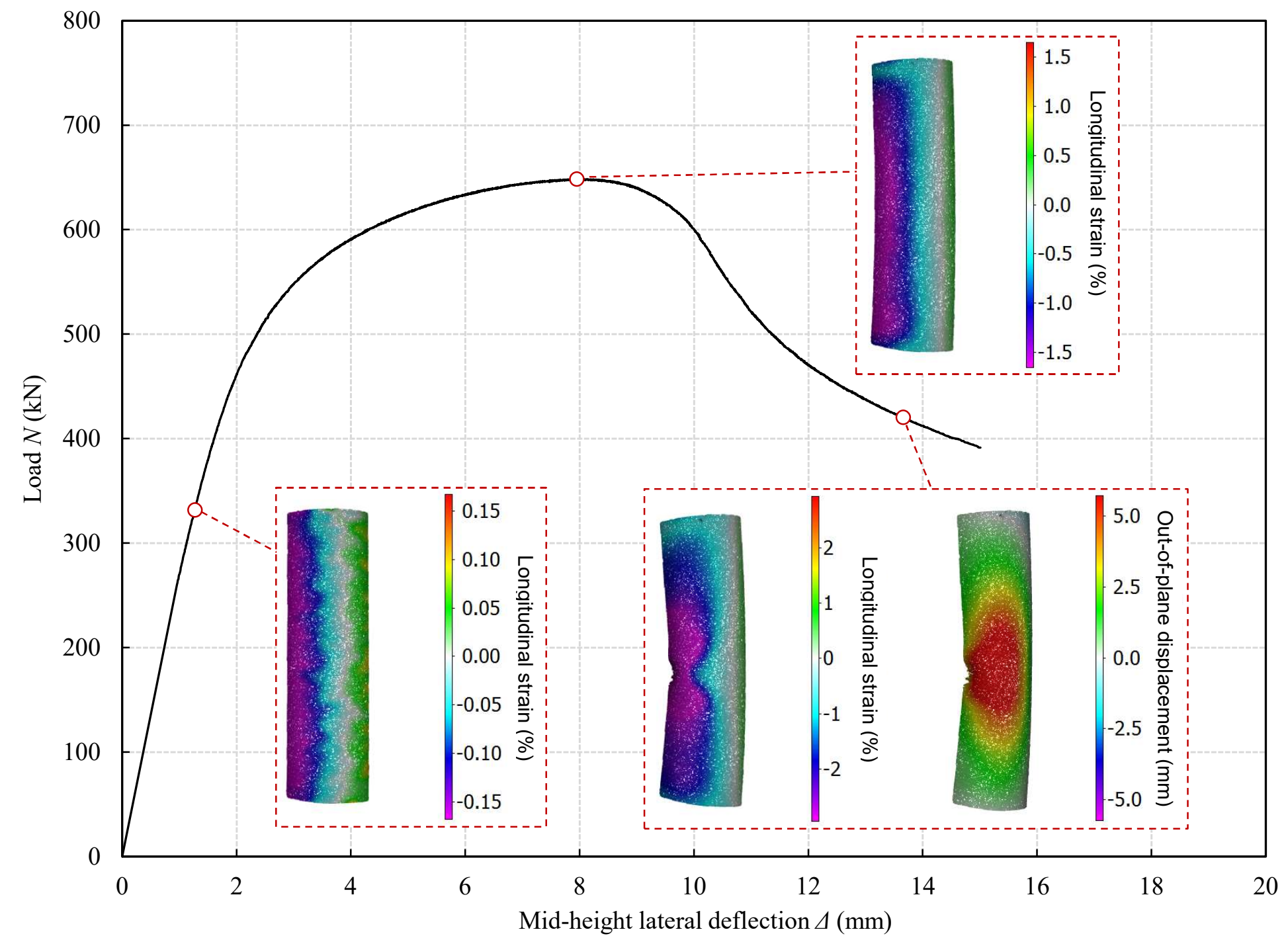

(a) Front 


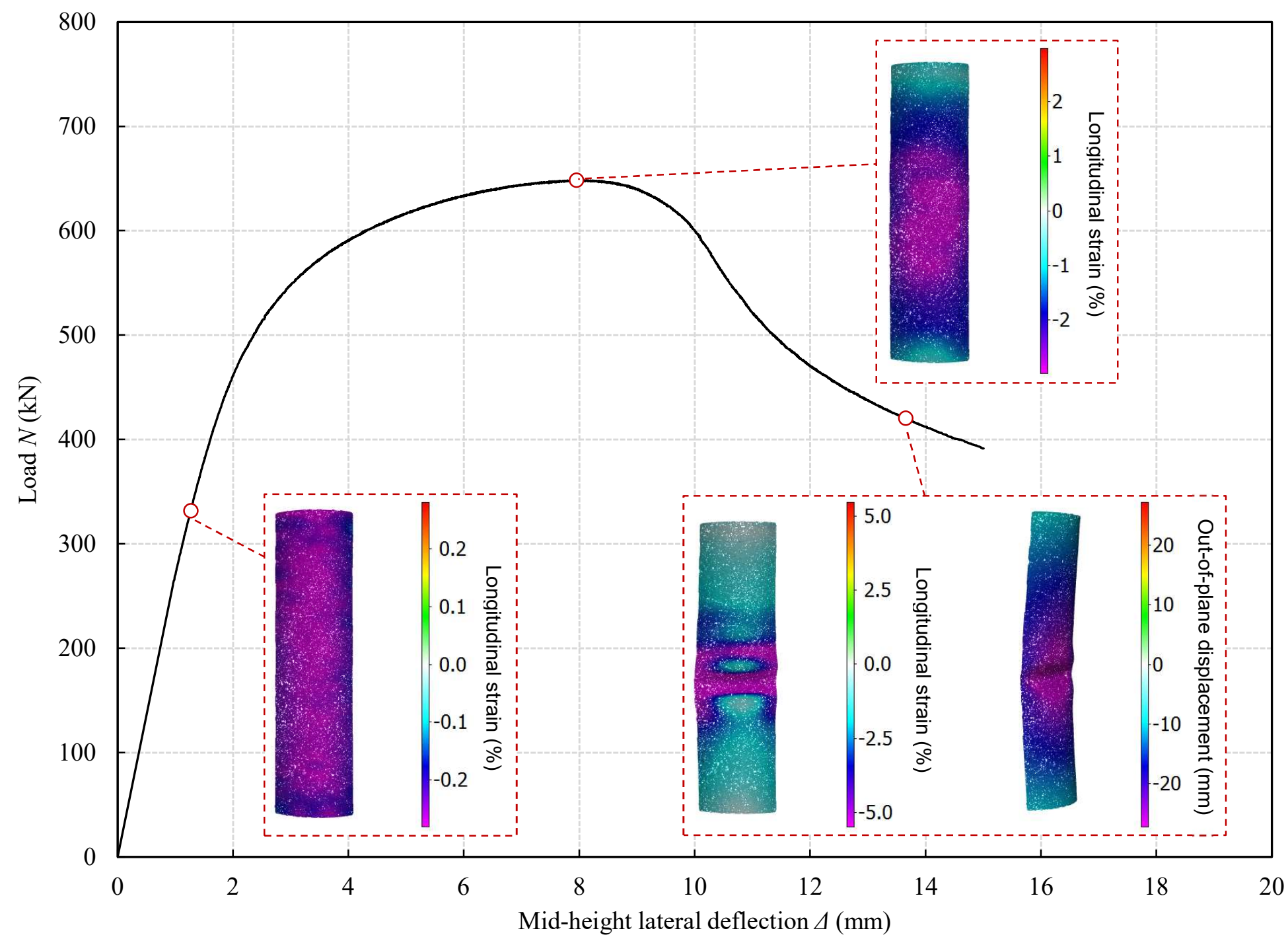

(b) Compressive side

Fig. 23. Typical DIC results from short beam-column tests (CSBC3-4, CHS 139.7 $\times 5, e_{\mathrm{n}}=85 \mathrm{~mm}$ ): (a) front and (b) compressive side 


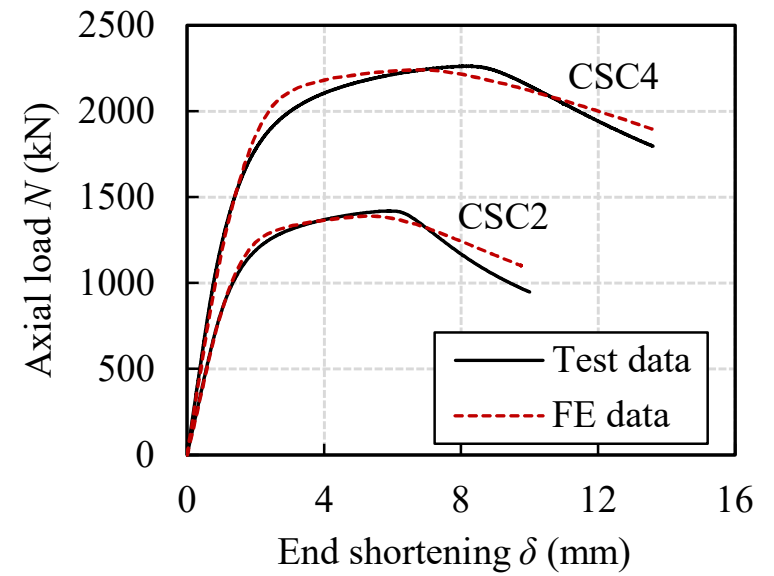

(a) Stub column tests

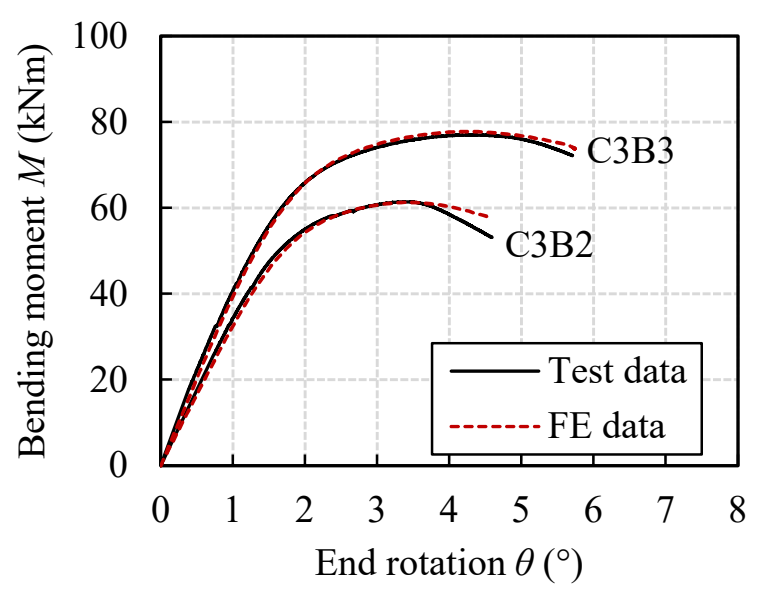

(c) Three-point bending tests

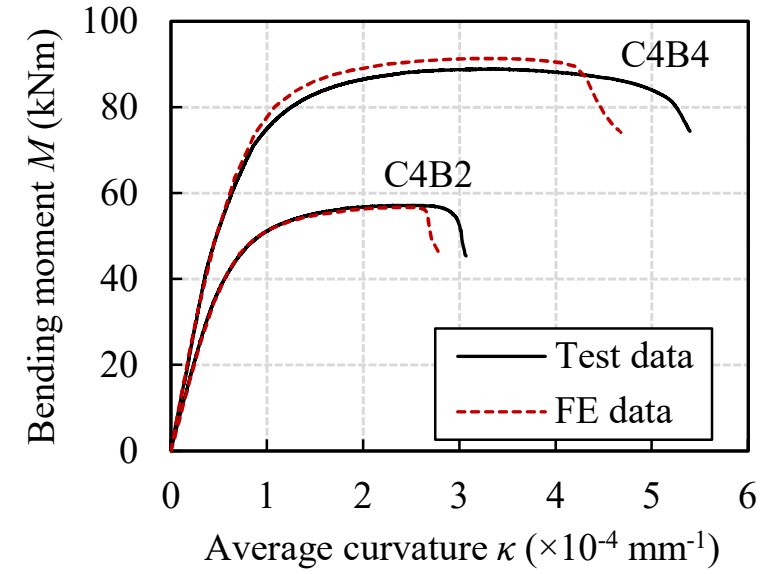

(b) Four-point bending tests

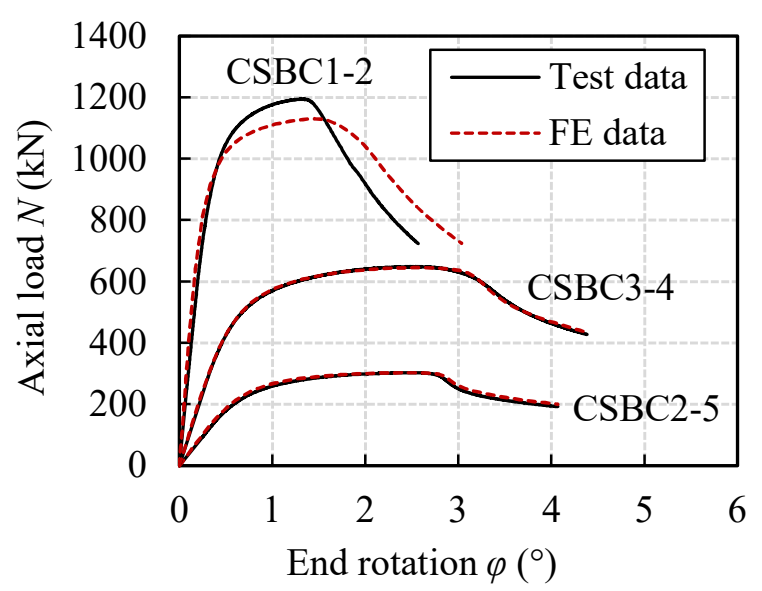

(d) Short beam-column tests

Fig. 24. Typical experimental and numerical load-deformation curves for (a) stub column tests, (b) four-point bending tests, (c) three-point bending tests and (d) short-beam column tests
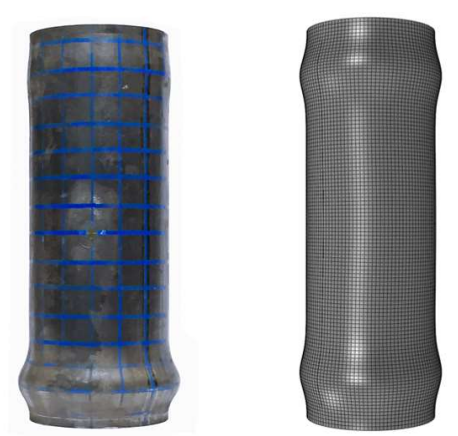

(a) Stub columns 

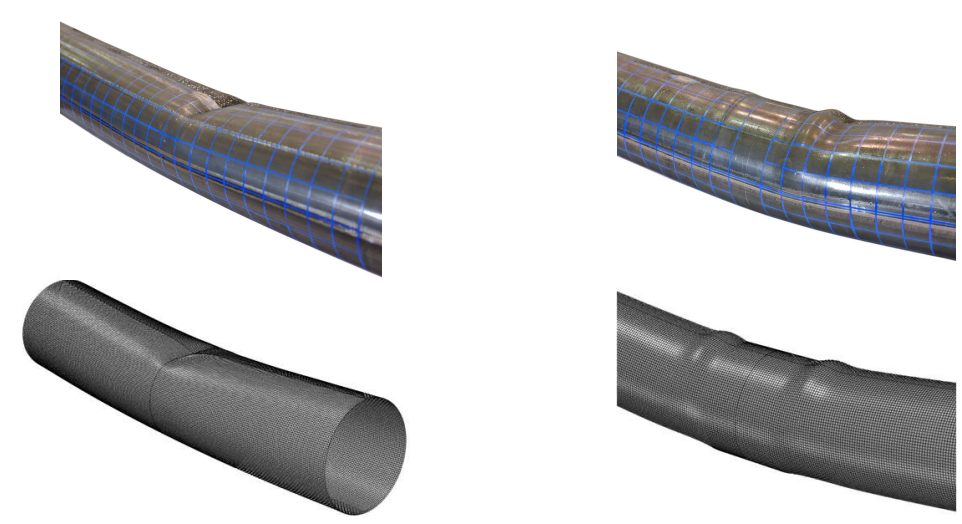

(b) Beams under four-point bending (left) and three-point bending (right)
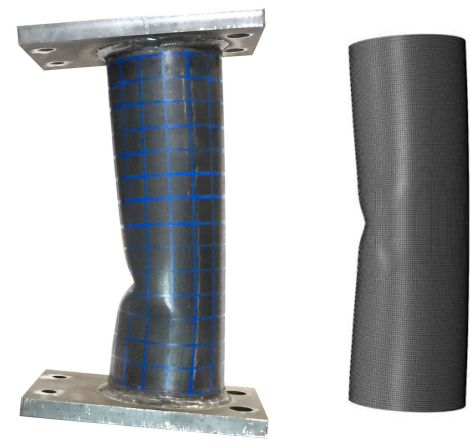

(c) Short beam-columns

Fig. 25. Typical experimental and numerical failure modes of (a) stub columns, (b) beams under fourpoint and three-point bending and (c) short beam-columns

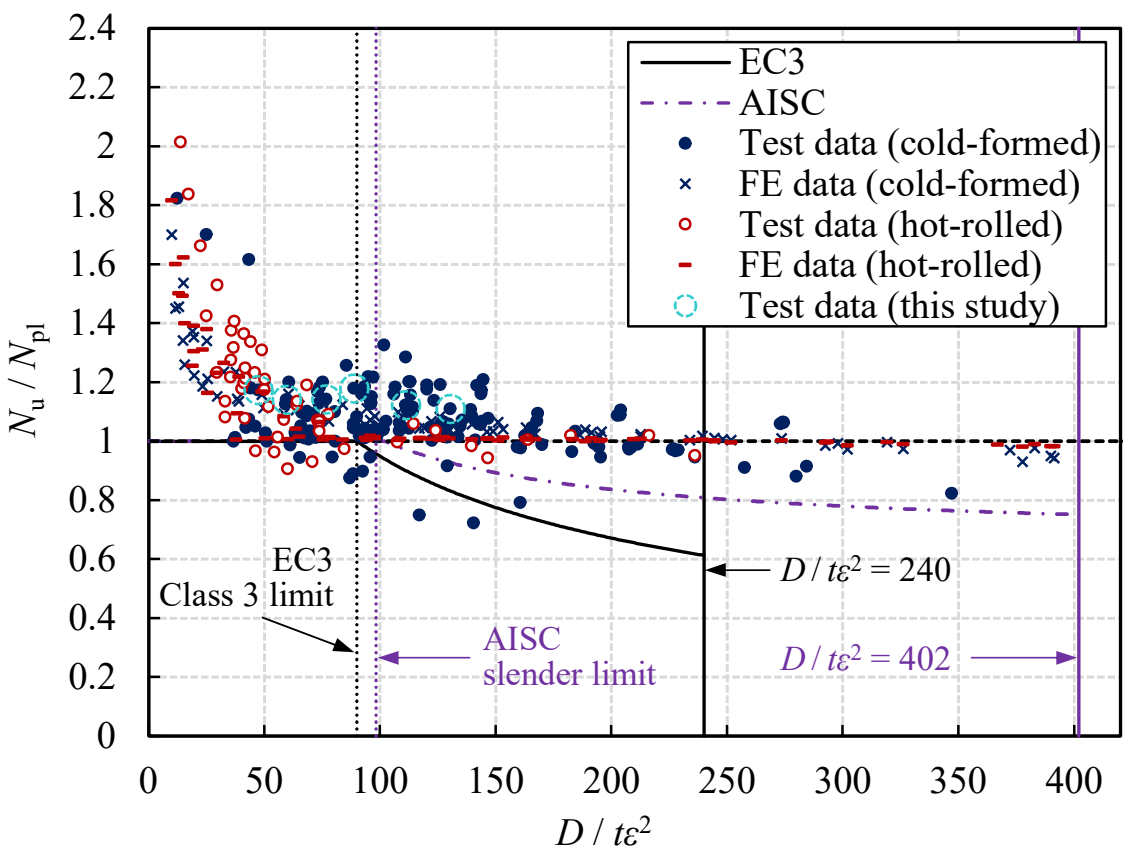

Fig. 26. Comparisons of test and FE resistances with codified slenderness limits and design curves for CHS in compression 


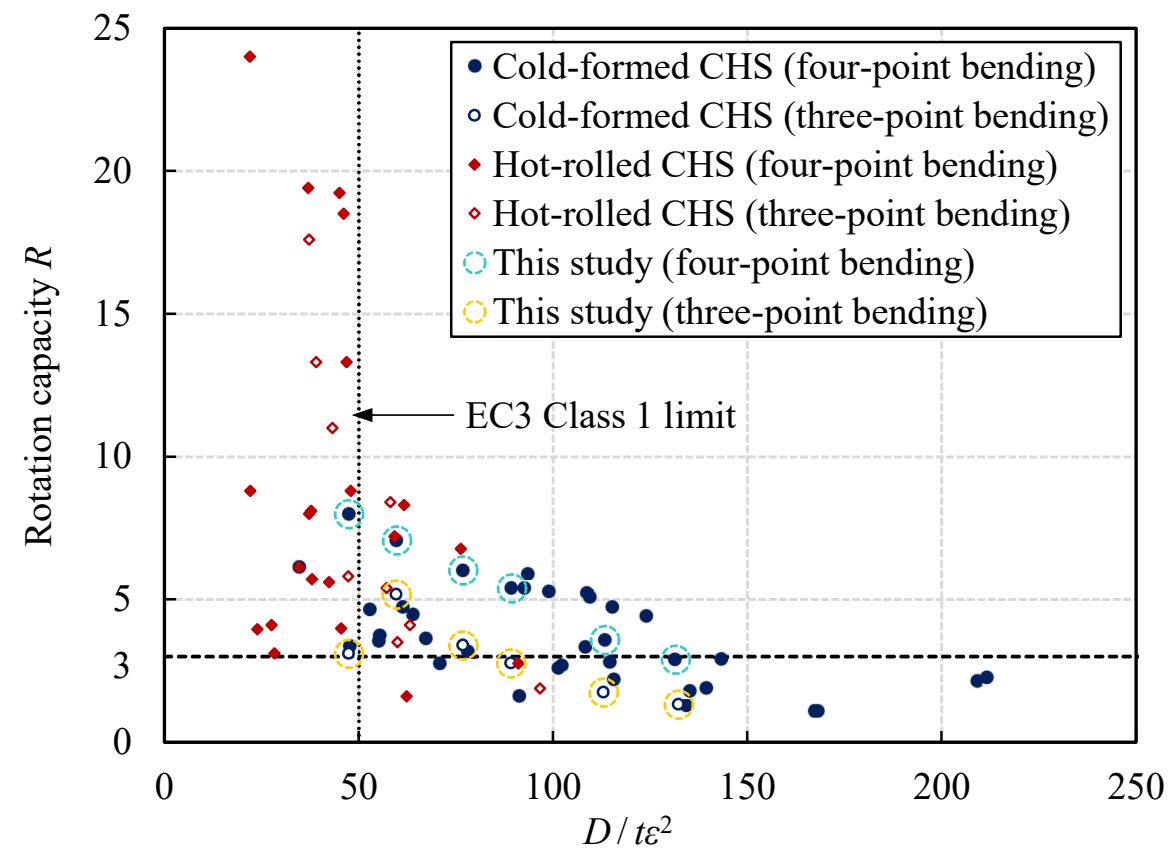

Fig. 27. Comparison of rotation capacities from tests with EC3 Class 1 limit for CHS

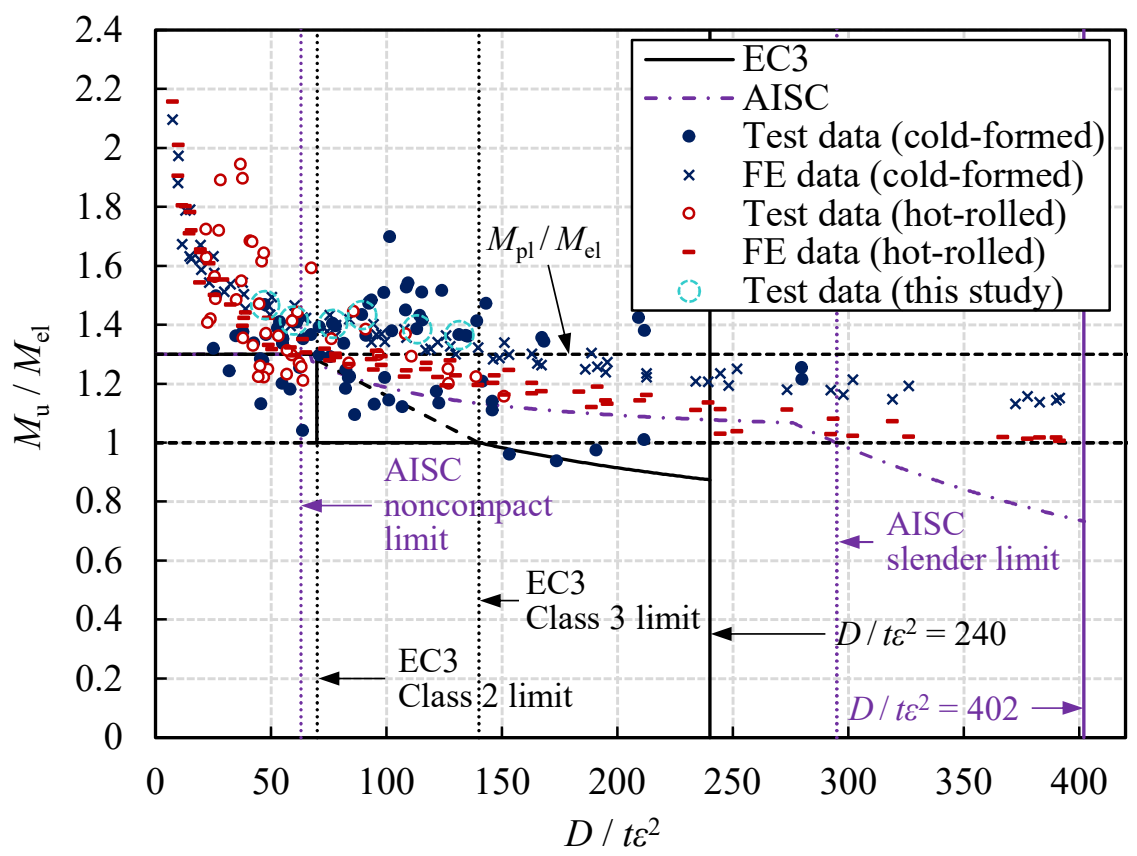

Fig. 28. Comparisons of test and FE resistances with codified slenderness limits and design curves for CHS in bending 


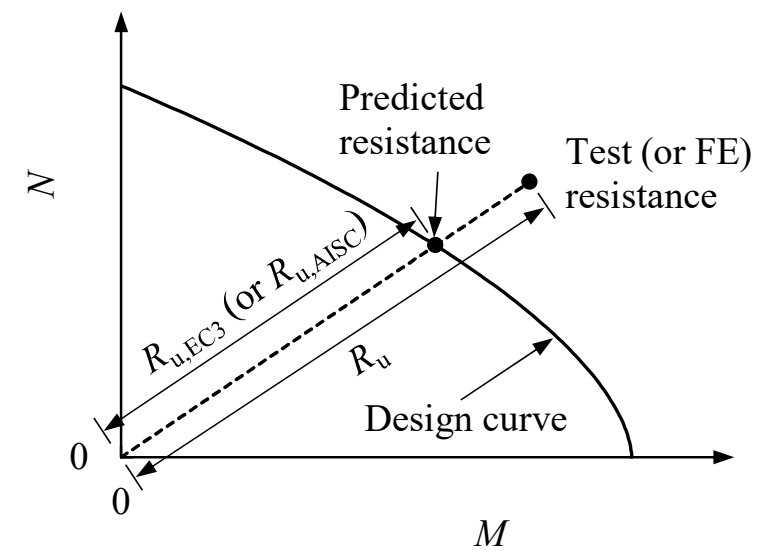

Fig. 29. Definition of $R_{\mathrm{u}}, R_{\mathrm{u}, \mathrm{EC} 3}$ and $R_{\mathrm{u}, \mathrm{AISC}}$

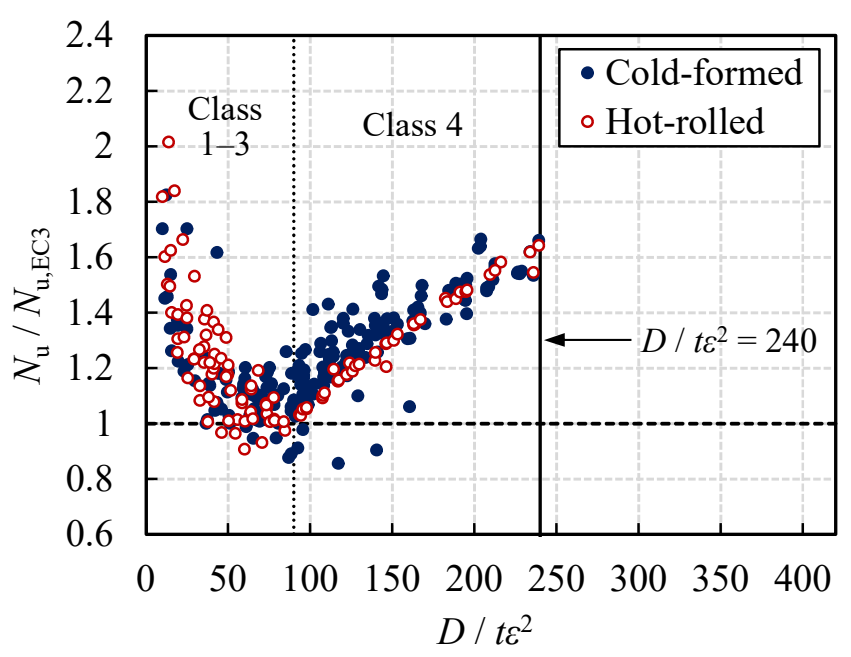

(a) EC3

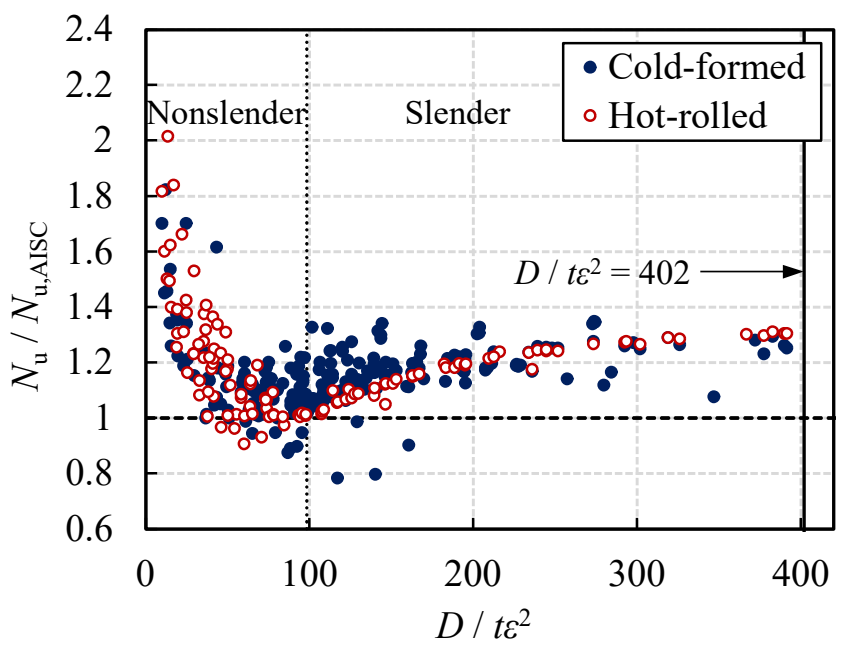

(b) AISC

Fig. 30. Comparisons of test and FE resistances in pure compression with predicted resistances from (a) EC3 and (b) AISC 


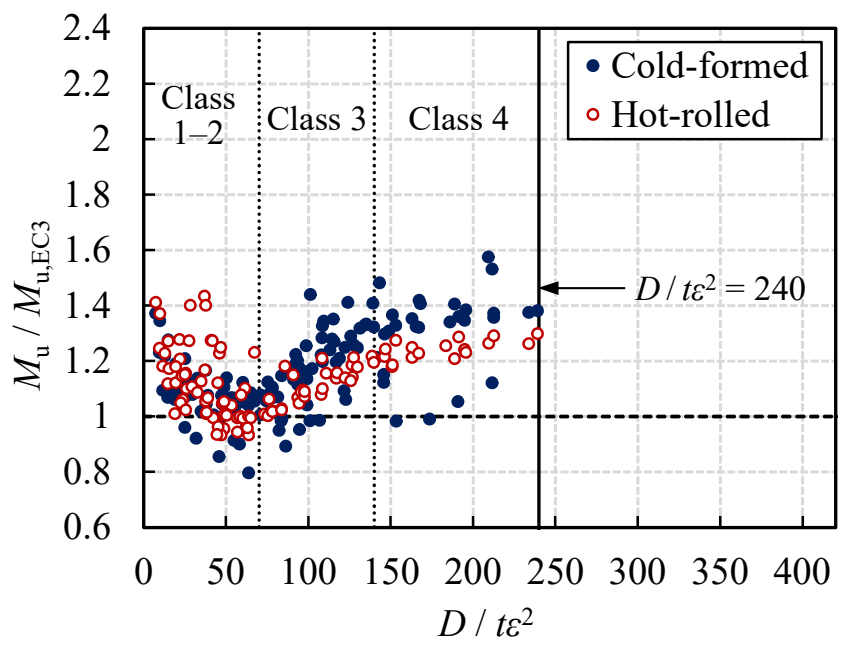

(a) EC3

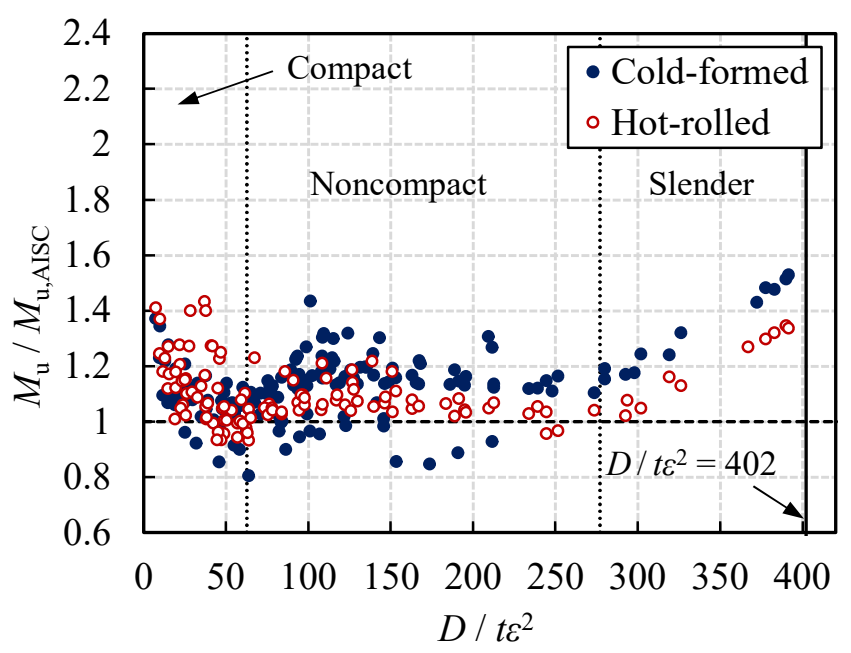

(b) AISC

Fig. 31. Comparisons of test and FE resistances in uniform bending with predicted resistances from (a) EC3 and (b) AISC 


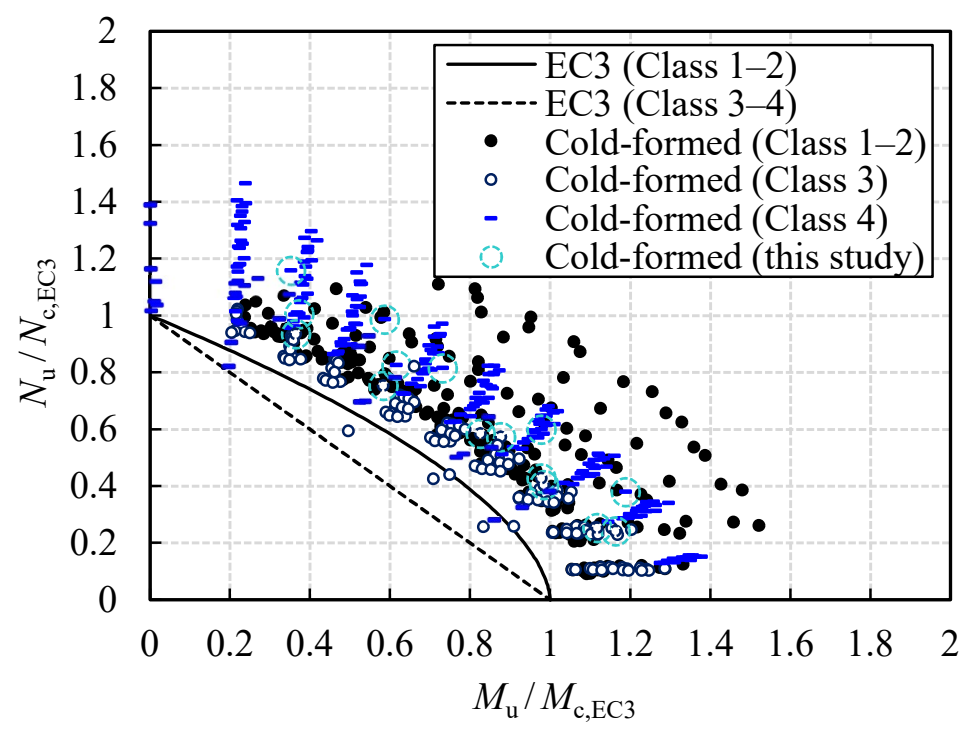

(a) EC3 (cold-formed CHS)

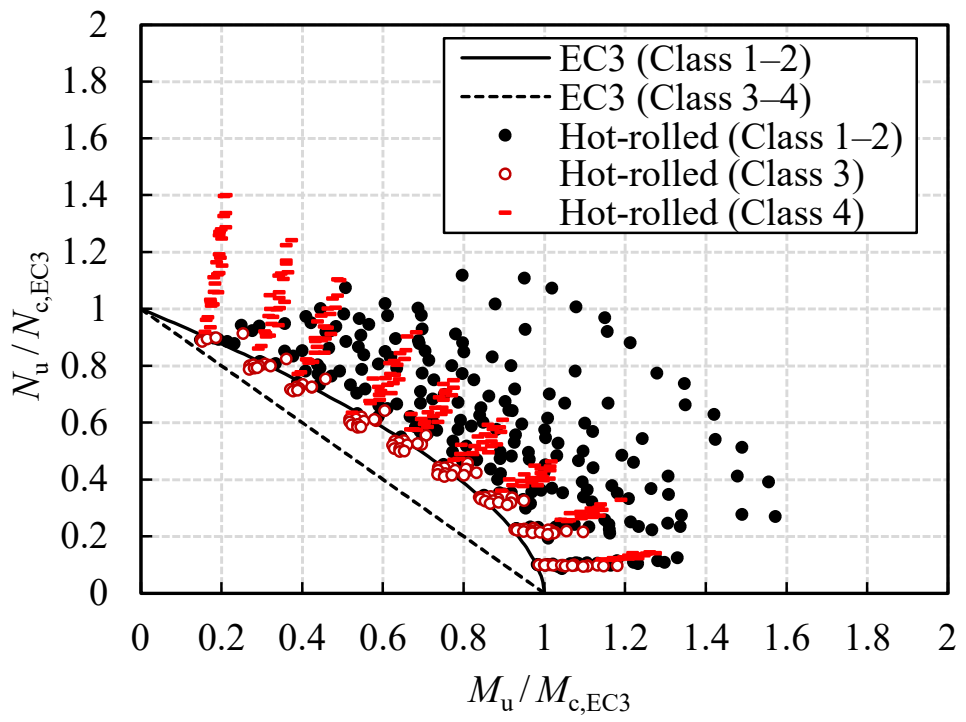

(b) EC3 (hot-rolled CHS)

Fig. 32. Comparisons of test and FE resistances under combined loading with EC3 design curves for (a) cold-formed CHS and (b) hot-rolled CHS 


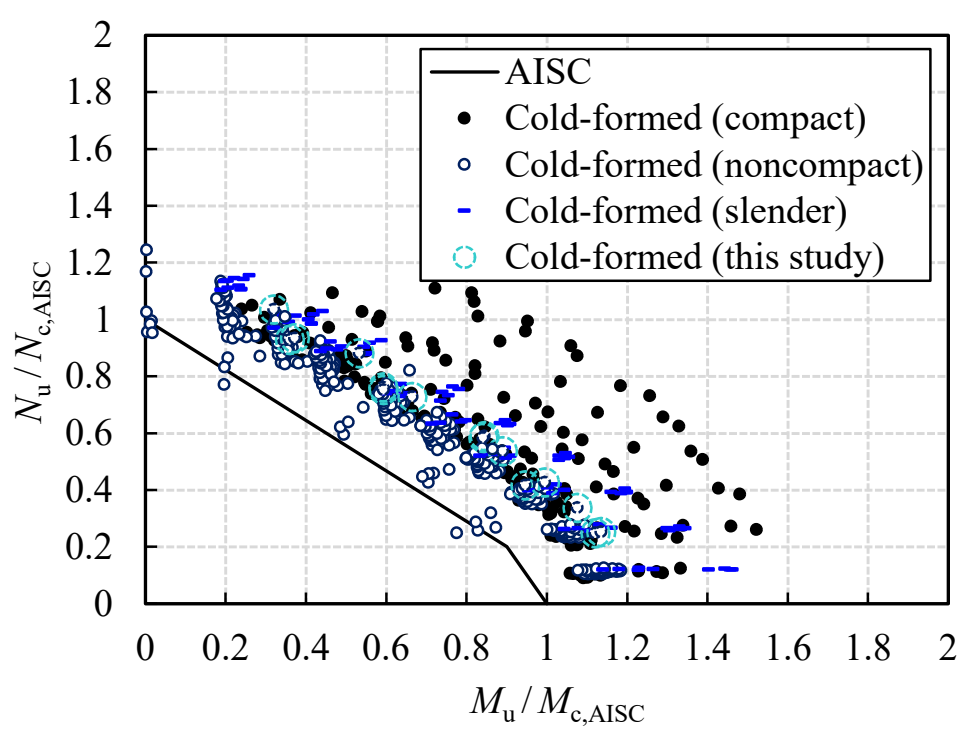

(a) AISC (cold-formed CHS)

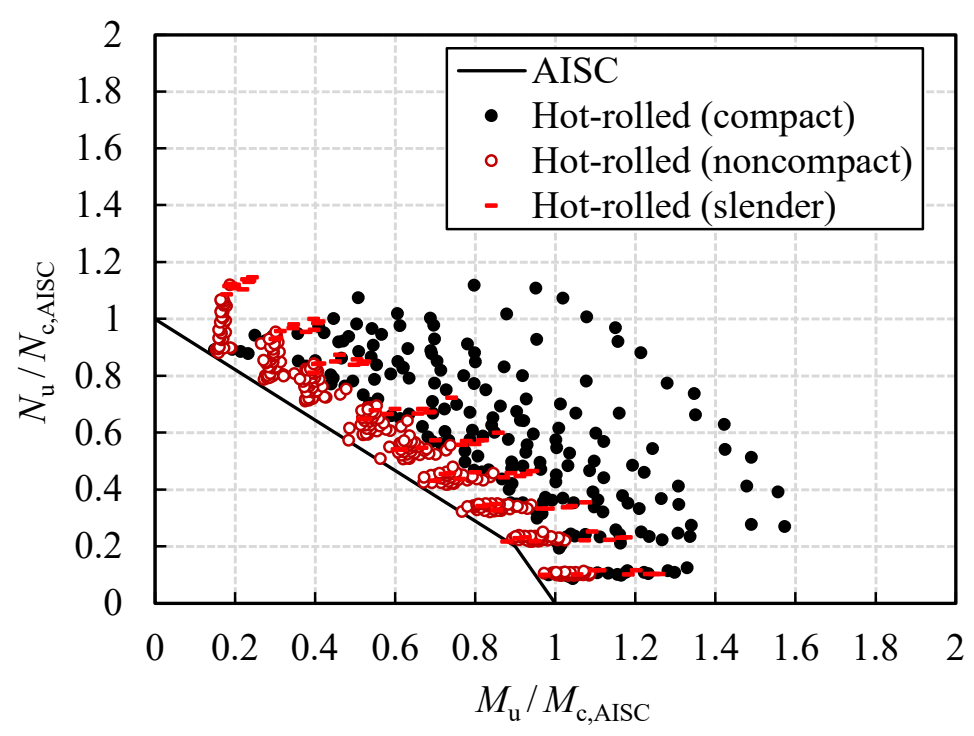

(b) AISC (hot-rolled CHS)

Fig. 33. Comparisons of test and FE resistances under combined loading with AISC design curves for (a) cold-formed CHS and (b) hot-rolled CHS 
Table 1 Overview of tested sections

\begin{tabular}{ccccc}
\hline Cross-section & Grade & $\begin{array}{c}\text { Section } \\
\text { ID }\end{array}$ & $\begin{array}{c}\text { Class } \\
\text { (in compression) }\end{array}$ & $\begin{array}{c}\text { Class } \\
\text { (in bending) }\end{array}$ \\
\hline CHS 168.3×4 & S700 & 1 & 4 & 3 \\
CHS 139.7×4 & S700 & 2 & 4 & 3 \\
CHS 139.7×5 & S700 & 3 & 3 & 3 \\
CHS 139.7×6 & S700 & 4 & 3 & 3 \\
CHS 139.7×8 & S700 & 5 & 2 & 2 \\
CHS 139.7×10 & S700 & 6 & 1 & 1 \\
\hline
\end{tabular}

Table 2 Chemical compositions of tested cross-sections from mill certificates

\begin{tabular}{|c|c|c|c|c|c|c|c|c|c|c|c|c|c|c|c|}
\hline Cross-section & $\mathrm{C}$ & $\mathrm{Si}$ & $\mathrm{Mn}$ & $\mathrm{P}$ & $\mathrm{S}$ & $\mathrm{Al}$ & $\mathrm{Nb}$ & $\mathrm{V}$ & $\mathrm{Cu}$ & $\mathrm{Cr}$ & $\mathrm{N}$ & $\mathrm{Ti}$ & Mo & $\mathrm{Ni}$ & B \\
\hline- & $\%$ & $\%$ & $\%$ & $\%$ & $\%$ & $\%$ & $\%$ & $\%$ & $\%$ & $\%$ & $\%$ & $\%$ & $\%$ & $\%$ & $\%$ \\
\hline CHS $168.3 \times 4$ & 0.06 & 0.18 & 1.70 & 0.007 & 0.002 & 0.034 & 0.055 & 0.039 & 0.201 & 0.066 & 0.004 & 0.100 & 0.020 & 0.042 & 0.0002 \\
\hline CHS $139.7 \times 4$ & 0.06 & 0.19 & 1.69 & 0.009 & 0.002 & 0.031 & 0.051 & 0.042 & 0.199 & 0.063 & 0.006 & 0.092 & 0.020 & 0.079 & 0.0004 \\
\hline CHS $139.7 \times 5$ & 0.06 & 0.20 & 1.69 & 0.008 & 0.002 & 0.032 & 0.051 & 0.044 & 0.192 & 0.062 & 0.004 & 0.096 & 0.010 & 0.054 & 0.0002 \\
\hline CHS $139.7 \times 6$ & 0.05 & 0.19 & 1.71 & 0.010 & 0.003 & 0.035 & 0.052 & 0.046 & 0.198 & 0.074 & 0.004 & 0.096 & 0.014 & 0.056 & 0.0002 \\
\hline CHS $139.7 \times 8$ & 0.06 & 0.20 & 1.80 & 0.011 & 0.002 & 0.039 & 0.084 & 0.011 & 0.014 & 0.045 & 0.004 & 0.112 & 0.008 & 0.035 & 0.0003 \\
\hline CHS $139.7 \times 10$ & 0.06 & 0.20 & 1.80 & 0.011 & 0.002 & 0.039 & 0.084 & 0.011 & 0.014 & 0.045 & 0.004 & 0.112 & 0.008 & 0.035 & 0.0003 \\
\hline
\end{tabular}


Table 3 Material properties of tested cross-sections from mill certificates

\begin{tabular}{cccc}
\hline $\begin{array}{c}\text { Cross-section } \\
-\end{array}$ & $\begin{array}{c}f_{\mathrm{y}, \mathrm{mill}} \\
\mathrm{N} / \mathrm{mm}^{2}\end{array}$ & $\begin{array}{c}f_{\mathrm{u} \text { mill }} \\
\mathrm{N} / \mathrm{mm}^{2}\end{array}$ & $\begin{array}{c}\varepsilon_{\mathrm{f}, \mathrm{mill}} \\
\%\end{array}$ \\
\hline CHS $168.3 \times 4$ & 737 & 847 & 19 \\
CHS $139.7 \times 4$ & 790 & 885 & 14 \\
CHS $139.7 \times 5$ & 774 & 865 & 13 \\
CHS $139.7 \times 6$ & 797 & 872 & 13 \\
CHS $139.7 \times 8$ & 788 & 852 & 15 \\
CHS $139.7 \times 10$ & 809 & 863 & 14 \\
\hline
\end{tabular}

Table 4 Average measured material properties from tensile coupon tests

\begin{tabular}{|c|c|c|c|c|c|c|c|}
\hline $\begin{array}{c}\text { Cross-section } \\
-\end{array}$ & $\begin{array}{c}E \\
\mathrm{~N} / \mathrm{mm}^{2}\end{array}$ & $\begin{array}{c}f_{\mathrm{y}} \\
\mathrm{N} / \mathrm{mm}^{2}\end{array}$ & $\begin{array}{c}f_{\mathrm{u}} \\
\mathrm{N} / \mathrm{mm}^{2}\end{array}$ & $\begin{array}{l}\varepsilon_{\mathrm{u}} \\
\%\end{array}$ & $\begin{array}{l}\varepsilon_{\mathrm{f}} \\
\%\end{array}$ & $\begin{array}{c}f_{\mathrm{u}} / f_{\mathrm{y}} \\
-\end{array}$ & $\begin{array}{c}\varepsilon_{\mathrm{u}} / \varepsilon_{\mathrm{y}} \\
-\end{array}$ \\
\hline CHS $168.3 \times 4$ & 211700 & 720.0 & 823.4 & 5.9 & 15.3 & 1.144 & 17.4 \\
\hline CHS $139.7 \times 4$ & 213300 & 742.4 & 842.3 & 4.7 & 15.9 & 1.135 & 13.5 \\
\hline CHS $139.7 \times 5$ & 212500 & 729.7 & 843.3 & 4.7 & 14.6 & 1.156 & 13.7 \\
\hline CHS $139.7 \times 6$ & 207900 & 779.0 & 866.7 & 2.8 & 13.7 & 1.113 & 7.5 \\
\hline CHS $139.7 \times 8$ & 205700 & 784.8 & 866.8 & 2.9 & 13.9 & 1.105 & 7.5 \\
\hline CHS $139.7 \times 10$ & 205600 & 787.6 & 877.5 & 2.2 & 13.8 & 1.114 & 5.7 \\
\hline
\end{tabular}


Table 5 Measured geometric properties of stub columns and stub column test results

\begin{tabular}{|c|c|c|c|c|c|c|c|c|c|c|c|}
\hline $\begin{array}{c}\text { Cross-section } \\
-\end{array}$ & $\begin{array}{c}\text { Specimen ID } \\
- \\
\end{array}$ & $\begin{array}{c}D \\
\mathrm{~mm}\end{array}$ & $\begin{array}{c}t \\
\mathrm{~mm} \\
\end{array}$ & $\begin{array}{c}L \\
\mathrm{~mm} \\
\end{array}$ & $\begin{array}{c}\omega_{1} \\
\mathrm{~mm}\end{array}$ & $\begin{array}{c}D / t \varepsilon^{2} \\
-\end{array}$ & $\begin{array}{l}N_{\mathrm{pl}} \\
\mathrm{kN}\end{array}$ & $\begin{array}{c}\delta_{\mathrm{pl}} \\
\mathrm{mm}\end{array}$ & $\begin{array}{l}N_{\mathrm{u}} \\
\mathrm{kN}\end{array}$ & $\begin{array}{c}\delta_{\mathrm{u}} \\
\mathrm{mm}\end{array}$ & $\begin{array}{c}N_{\mathrm{u}} / N_{\mathrm{pl}} \\
-\end{array}$ \\
\hline CHS $168.3 \times 4$ & $\mathrm{CSC} 1$ & 168.42 & 3.95 & 505.31 & 0.12 & 130.5 & 1471.1 & 1.72 & 1634.6 & 5.1 & 1.111 \\
\hline CHS 139.7×4 & $\mathrm{CSC} 2$ & 140.10 & 3.98 & 420.28 & 0.10 & 111.2 & 1263.6 & 1.46 & 1419.1 & 5.9 & 1.123 \\
\hline CHS $139.7 \times 5$ & CSC3 & 140.42 & 4.91 & 420.08 & 0.08 & 88.9 & 1524.1 & 1.44 & 1798.5 & 7.1 & 1.180 \\
\hline CHS $139.7 \times 6$ & $\mathrm{CSC} 4$ & 139.82 & 6.04 & 420.02 & 0.15 & 76.7 & 1978.4 & 1.57 & 2261.5 & 8.2 & 1.143 \\
\hline CHS $139.7 \times 8$ & CSC5 & 140.06 & 7.85 & 420.25 & 0.12 & 59.6 & 2557.4 & 1.60 & 2919.6 & 10.6 & 1.142 \\
\hline CHS $139.7 \times 10$ & CSC6 & 140.29 & 9.93 & 419.99 & 0.10 & 47.4 & 3202.4 & 1.61 & 3760.0 & 13.9 & 1.174 \\
\hline
\end{tabular}

Table 6 Measured geometric properties of four-point bending specimens and four-point bending test results

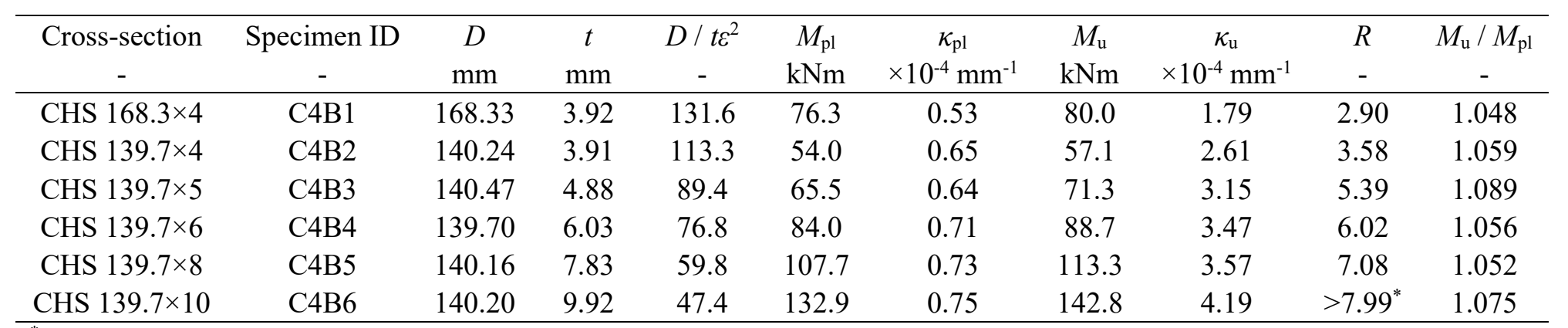

${ }^{*}$ Test was terminated before moment dropped below $M_{\mathrm{pl}}$ on descending branch. 
Table 7 Measured geometric properties of three-point bending specimens and three-point bending test results

\begin{tabular}{|c|c|c|c|c|c|c|c|c|c|c|}
\hline $\begin{array}{c}\text { Cross-section } \\
- \\
\end{array}$ & $\begin{array}{c}\text { Specimen ID } \\
- \\
\end{array}$ & $\begin{array}{c}D \\
\mathrm{~mm}\end{array}$ & $\begin{array}{c}t \\
\mathrm{~mm} \\
\end{array}$ & $\begin{array}{c}D / t \varepsilon^{2} \\
- \\
\end{array}$ & $\begin{array}{c}M_{\mathrm{pl}} \\
\mathrm{kNm} \\
\end{array}$ & $\underset{\circ}{\theta_{\mathrm{pl}}}$ & $\begin{array}{c}M_{\mathrm{u}} \\
\mathrm{kNm}\end{array}$ & $\begin{array}{c}\theta_{\mathrm{u}} \\
\circ\end{array}$ & $\begin{array}{l}R \\
- \\
\end{array}$ & $\begin{array}{c}M_{\mathrm{u}} / M_{\mathrm{pl}} \\
- \\
\end{array}$ \\
\hline CHS $168.3 \times 4$ & C3B1 & 168.35 & 3.90 & 132.3 & 76.0 & 1.33 & 84.9 & 2.43 & 1.32 & 1.118 \\
\hline CHS $139.7 \times 4$ & C3B2 & 140.12 & 3.92 & 112.9 & 54.0 & 1.64 & 61.4 & 3.41 & 1.74 & 1.137 \\
\hline CHS $139.7 \times 5$ & C3B3 & 140.47 & 4.89 & 89.2 & 65.6 & 1.62 & 77.0 & 4.26 & $>2.77^{*}$ & 1.173 \\
\hline CHS $139.7 \times 6$ & C3B3 & 139.56 & 6.02 & 76.8 & 83.7 & 1.80 & 96.5 & 5.05 & 3.39 & 1.153 \\
\hline CHS $139.7 \times 8$ & C3B5 & 140.16 & 7.84 & 59.7 & 107.8 & 1.85 & 124.9 & 6.23 & $>5.18^{*}$ & 1.158 \\
\hline CHS $139.7 \times 10$ & C3B6 & 140.22 & 9.90 & 47.5 & 132.7 & 1.88 & 154.4 & 6.78 & $>3.10^{*}$ & 1.164 \\
\hline
\end{tabular}

${ }^{*}$ Tests was terminated before moment dropped below $M_{\mathrm{pl}}$ on descending branch. 
Table 8 Measured geometric properties of short beam-columns and short beam-column test results

\begin{tabular}{|c|c|c|c|c|c|c|c|c|c|c|c|c|}
\hline $\begin{array}{c}\text { Cross-section } \\
- \\
\end{array}$ & $\begin{array}{c}\text { Specimen ID } \\
- \\
\end{array}$ & $\begin{array}{c}D \\
\mathrm{~mm}\end{array}$ & $\begin{array}{c}t \\
\mathrm{~mm} \\
\end{array}$ & $\begin{array}{c}L \\
\mathrm{~mm}\end{array}$ & $\begin{array}{c}\omega_{1} \\
\mathrm{~mm} \\
\end{array}$ & $\begin{array}{c}t_{\mathrm{ep}} \\
\mathrm{mm}\end{array}$ & $\begin{array}{c}e_{\mathrm{n}} \\
\mathrm{mm}\end{array}$ & $\begin{array}{c}e_{\mathrm{m}} \\
\mathrm{mm}\end{array}$ & $\begin{array}{l}N_{\mathrm{u}} \\
\mathrm{kN} \\
\end{array}$ & $\begin{array}{c}\Delta_{\mathrm{u}} \\
\mathrm{mm}\end{array}$ & $\begin{array}{c}\varphi_{\underline{u}} \\
\circ \\
\end{array}$ & $\begin{array}{l}M_{\mathrm{tot}, \mathrm{u}} \\
\mathrm{kNm}\end{array}$ \\
\hline CHS $168.3 \times 4$ & CSBC1-1 & 168.35 & 3.93 & 505.04 & 0.19 & 15 & 10 & 10.37 & 1400.6 & 4.92 & 1.35 & 21.4 \\
\hline CHS $168.3 \times 4$ & CSBC1-2 & 168.37 & 3.93 & 505.09 & 0.25 & 20 & 25 & 25.02 & 1194.7 & 4.86 & 1.33 & 35.7 \\
\hline CHS $168.3 \times 4$ & CSBC1-3 & 168.43 & 3.93 & 505.14 & 0.16 & 20 & 40 & 40.22 & 985.2 & 4.98 & 1.54 & 44.5 \\
\hline CHS $168.3 \times 4$ & CSBC1-4 & 168.07 & 3.93 & 505.35 & 0.31 & 25 & 75 & 76.02 & 726.8 & 5.88 & 1.78 & 59.5 \\
\hline CHS $168.3 \times 4$ & CSBC1-5 & 168.59 & 3.91 & 504.60 & 0.29 & 25 & 150 & 151.01 & 455.9 & 6.77 & 1.94 & 71.9 \\
\hline CHS $139.7 \times 4$ & CSBC2-1 & 140.06 & 3.95 & 419.15 & 0.14 & 15 & 10 & 9.94 & 1129.2 & 5.42 & 1.87 & 17.3 \\
\hline CHS $139.7 \times 4$ & CSBC2-2 & 140.11 & 3.94 & 419.42 & 0.16 & 15 & 25 & 25.02 & 924.4 & 5.92 & 2.05 & 28.6 \\
\hline CHS $139.7 \times 4$ & CSBC2-3 & 140.02 & 3.94 & 420.01 & 0.33 & 20 & 50 & 49.43 & 715.4 & 7.43 & 2.45 & 40.7 \\
\hline CHS $139.7 \times 4$ & CSBC2-4 & 140.13 & 3.94 & 420.16 & 0.18 & 20 & 85 & 83.64 & 505.6 & 6.70 & 2.41 & 45.7 \\
\hline CHS $139.7 \times 4$ & CSBC2-5 & 140.08 & 3.95 & 419.80 & 0.17 & 25 & 170 & 171.24 & 302.7 & 7.81 & 2.49 & 54.2 \\
\hline CHS $139.7 \times 5$ & CSBC3-1 & 140.38 & 4.88 & 420.24 & 0.11 & 15 & 10 & 9.72 & 1417.2 & 5.99 & 1.89 & 22.3 \\
\hline CHS $139.7 \times 5$ & CSBC3-2 & 140.35 & 4.86 & 420.83 & 0.11 & 15 & 25 & 24.51 & 1136.6 & 6.61 & 2.31 & 35.4 \\
\hline CHS $139.7 \times 5$ & CSBC3-3 & 140.34 & 4.89 & 419.66 & 0.13 & 20 & 50 & 49.69 & 887.8 & 7.23 & 2.45 & 50.5 \\
\hline CHS $139.7 \times 5$ & CSBC3-4 & 140.37 & 4.88 & 420.16 & 0.15 & 25 & 85 & 83.84 & 648.4 & 8.16 & 2.54 & 59.7 \\
\hline CHS $139.7 \times 5$ & CSBC3-5 & 140.37 & 4.86 & 420.00 & 0.17 & 25 & 170 & 168.93 & 381.6 & 8.78 & 3.08 & 67.8 \\
\hline
\end{tabular}


Table 9 Comparisons of test results with FE results for varying local imperfection patterns and amplitudes

\begin{tabular}{|c|c|c|c|c|c|c|c|c|c|c|}
\hline \multirow{2}{*}{$\begin{array}{l}\text { Loading } \\
\text { scenario }\end{array}$} & \multirow{2}{*}{$\begin{array}{c}\text { No. of } \\
\text { data }\end{array}$} & \multirow{2}{*}{$\begin{array}{l}\text { Evaluation } \\
\text { parameter }\end{array}$} & \multicolumn{2}{|c|}{ GMNA } & \multicolumn{2}{|c|}{ LBA- $t_{\text {mod }}$, Eq. (13) } & \multicolumn{2}{|c|}{ LBA- $t$, Eq. (13) } & \multicolumn{2}{|c|}{ LBA- $t_{\text {mod }}$, measured $\omega_{1}$} \\
\hline & & & $N_{\mathrm{u}, \mathrm{FE}} / N_{\mathrm{u}, \text { test }}$ & $M_{\mathrm{u}, \mathrm{FE}} / M_{\mathrm{u}, \text { test }}$ & $N_{\mathrm{u}, \mathrm{FE}} / N_{\mathrm{u}, \text { test }}$ & $M_{\mathrm{u}, \mathrm{FE}} / M_{\mathrm{u}, \text { test }}$ & $N_{\mathrm{u}, \mathrm{FE}} / N_{\mathrm{u}, \text { test }}$ & $M_{\mathrm{u}, \mathrm{FE}} / M_{\mathrm{u}, \mathrm{test}}$ & $N_{\mathrm{u}, \mathrm{FE}} / N_{\mathrm{u}, \text { test }}$ & $M_{\mathrm{u}, \mathrm{FE}} / M_{\mathrm{u}, \mathrm{test}}$ \\
\hline \multirow{2}{*}{$\begin{array}{c}\text { Axial } \\
\text { compression }\end{array}$} & \multirow{2}{*}{6} & Mean & 0.982 & - & 0.982 & - & 0.982 & - & 0.982 & - \\
\hline & & $\mathrm{COV}$ & 0.012 & - & 0.012 & - & 0.012 & - & 0.012 & - \\
\hline \multirow{2}{*}{$\begin{array}{l}\text { Four-point } \\
\text { bending }\end{array}$} & \multirow{2}{*}{6} & Mean & - & 1.014 & - & 1.012 & - & 0.990 & - & - \\
\hline & & $\mathrm{COV}$ & - & 0.021 & - & 0.022 & - & 0.041 & - & - \\
\hline \multirow{2}{*}{$\begin{array}{l}\text { Three-point } \\
\text { bending }\end{array}$} & \multirow{2}{*}{6} & Mean & & 1.016 & - & 1.010 & - & 1.005 & - & - \\
\hline & & $\mathrm{COV}$ & & 0.008 & - & 0.011 & - & 0.012 & - & - \\
\hline \multirow{2}{*}{$\begin{array}{c}\text { Combined } \\
\text { loading }\end{array}$} & \multirow{2}{*}{15} & Mean & 0.994 & 1.007 & 0.989 & 0.990 & 0.937 & 0.876 & 0.990 & 0.995 \\
\hline & & $\mathrm{COV}$ & 0.021 & 0.021 & 0.020 & 0.021 & 0.027 & 0.066 & 0.020 & 0.024 \\
\hline
\end{tabular}

Table 10 Summary of codified slenderness limits in terms of $D / t \varepsilon^{2}$ (or $D / t$ ) for (a) Eurocode 3 and (b) American Specification

(a) Eurocode 3

\begin{tabular}{|c|c|c|c|c|c|c|}
\hline \multirow{2}{*}{$\begin{array}{l}\text { Loading } \\
\text { scenario }\end{array}$} & \multicolumn{3}{|c|}{ Current EC3 - EN 1993-1-1:2005 } & \multicolumn{3}{|c|}{ Upcoming EC3 - prEN 1993-1-1:2018 } \\
\hline & Class 1 & Class 2 & Class 3 & Class 1 & Class 2 & Class 3 \\
\hline $\begin{array}{c}\text { Axial } \\
\text { compression }\end{array}$ & \multirow{3}{*}{$\begin{array}{c}50 \\
\left(0.056 \frac{E}{f_{\mathrm{y}}}\right)\end{array}$} & \multirow{3}{*}{$\begin{array}{c}70 \\
\left(0.078 \frac{E}{f_{\mathrm{y}}}\right)\end{array}$} & \multirow{3}{*}{$\begin{array}{c}90 \\
\left(0.101 \frac{E}{f_{\mathrm{y}}}\right)\end{array}$} & \multirow{3}{*}{$\begin{array}{c}50 \\
\left(0.056 \frac{E}{f_{\mathrm{y}}}\right)\end{array}$} & \multirow{3}{*}{$\begin{array}{c}70 \\
\left(0.078 \frac{E}{f_{\mathrm{y}}}\right)\end{array}$} & $90\left(0.101 \frac{E}{f_{\mathrm{y}}}\right)$ \\
\hline Bending & & & & & & $140\left(0.157 \frac{E}{f_{\mathrm{y}}}\right)$ \\
\hline $\begin{array}{c}\text { Compression } \\
+ \\
\text { bending } \\
\end{array}$ & & & & & & $\frac{2520}{5 \psi+23}\left(\frac{2.82}{5 \psi+23} \frac{E}{f_{\mathrm{y}}}\right)$ \\
\hline
\end{tabular}


(b) American Specification

\begin{tabular}{c|c|c}
\hline \multirow{2}{*}{$\begin{array}{c}\text { Loading } \\
\text { scenario }\end{array}$} & \multicolumn{2}{|c}{ American Specification - ANSI/AISC 360-16 } \\
\hline \multirow{2}{*}{$\begin{array}{c}\text { Axial } \\
\text { compression }\end{array}$} & \multicolumn{2}{|c}{ Nonslender/slender } \\
\cline { 2 - 3 } & \multicolumn{2}{|c}{$98.3\left(0.11 \frac{E}{f_{\mathrm{y}}}\right)$} \\
\hline \multirow{2}{*}{ Bending } & Compact/noncompact & Noncompact/slender \\
\cline { 2 - 3 } & $62.6\left(0.07 \frac{E}{f_{\mathrm{y}}}\right)$ & $277.0\left(0.31 \frac{E}{f_{\mathrm{y}}}\right)$ \\
\hline
\end{tabular}

Table 11 Summary of cross-section design rules for CHS in prEN 1993-1-1:2018 [25]

\begin{tabular}{|c|c|c|c|}
\hline \multirow{2}{*}{$\begin{array}{l}\text { Loading } \\
\text { scenario }\end{array}$} & \multicolumn{3}{|c|}{ Eurocode 3 - prEN 1993-1-1:2018 } \\
\hline & Class $1 \& 2$ & Class 3 & Class 4 \\
\hline $\begin{array}{c}\text { Axial } \\
\text { compression }\end{array}$ & $N_{\mathrm{c}, \mathrm{Rd}}=N_{\mathrm{pl}, \mathrm{Rd}}=\frac{A f_{\mathrm{y}}}{\gamma_{\mathrm{M} 0}}$ & & $\begin{array}{l}N_{\mathrm{c}, \mathrm{Rd}}=N_{\mathrm{eff}, \mathrm{Rd}}=\frac{A_{\mathrm{eff}} f_{\mathrm{y}}}{\gamma_{\mathrm{M} 0}} \\
\text { where: } \\
\quad A_{\text {eff }}=A \sqrt{\frac{90 \varepsilon^{2}}{D / t}} \text { for } 90<D / t \varepsilon^{2} \leq 240\end{array}$ \\
\hline Bending & $M_{\mathrm{c}, \mathrm{Rd}}=M_{\mathrm{pl}, \mathrm{Rd}}=\frac{W_{\mathrm{pl}} f_{\mathrm{y}}}{\gamma_{\mathrm{M} 0}}$ & $\begin{array}{l}M_{\mathrm{c}, \mathrm{Rd}}=M_{\mathrm{el}, \mathrm{Rd}}=\frac{W_{\mathrm{el}} f_{\mathrm{y}}}{\gamma_{\mathrm{M} 0}} \text { or } M_{\mathrm{c}, \mathrm{Rd}}=M_{\mathrm{ep}, \mathrm{Rd}}=\frac{W_{\mathrm{ep}} f_{\mathrm{y}}}{\gamma_{\mathrm{M} 0}} \\
\text { where: } \\
W_{\mathrm{ep}}=W_{\mathrm{pl}}-\left(W_{\mathrm{pl}}-W_{\mathrm{el}}\right) \beta_{\mathrm{ep}} \text { for } 70<D / t \varepsilon^{2} \leq 140 \\
\beta_{\mathrm{ep}}=\max \left(\frac{D / t-70 \varepsilon^{2}}{70 \varepsilon^{2}} ; 0\right) \text { but } \beta_{\mathrm{ep}} \leq 1\end{array}$ & $\begin{array}{l}M_{\mathrm{c}, \mathrm{Rd}}=M_{\mathrm{eff}, \mathrm{Rd}}=\frac{W_{\mathrm{eff}} f_{\mathrm{y}}}{\gamma_{\mathrm{M} 0}} \\
\text { where: } \\
W_{\text {eff }}=W_{\mathrm{el}} \sqrt[4]{\frac{140 \varepsilon^{2}}{D / t}} \text { for } 140<D / t \varepsilon^{2} \leq 240\end{array}$ \\
\hline $\begin{array}{c}\text { Compression } \\
+ \\
\text { bending }\end{array}$ & $\left(\frac{N_{\mathrm{Ed}}}{N_{\mathrm{pl}, \mathrm{Rd}}}\right)^{1.7}+\frac{M_{\mathrm{Ed}}}{M_{\mathrm{pl}, \mathrm{Rd}}} \leq 1$ & $\frac{N_{\mathrm{Ed}}}{N_{\mathrm{pl}, \mathrm{Rd}}}+\frac{M_{\mathrm{Ed}}}{M_{\mathrm{el}, \mathrm{Rd}}} \leq 1$ or $\frac{N_{\mathrm{Ed}}}{N_{\mathrm{pl}, \mathrm{Rd}}}+\frac{M_{\mathrm{Ed}}}{M_{\mathrm{ep}, \mathrm{Rd}}} \leq 1$ & $\frac{N_{\mathrm{Ed}}}{N_{\mathrm{eff}, \mathrm{Rd}}}+\frac{M_{\mathrm{Ed}}}{M_{\mathrm{eff}, \mathrm{Rd}}} \leq 1$ \\
\hline
\end{tabular}


Table 12 Summary of cross-section design rules for CHS in ANSI/AISC 360-16 [10]

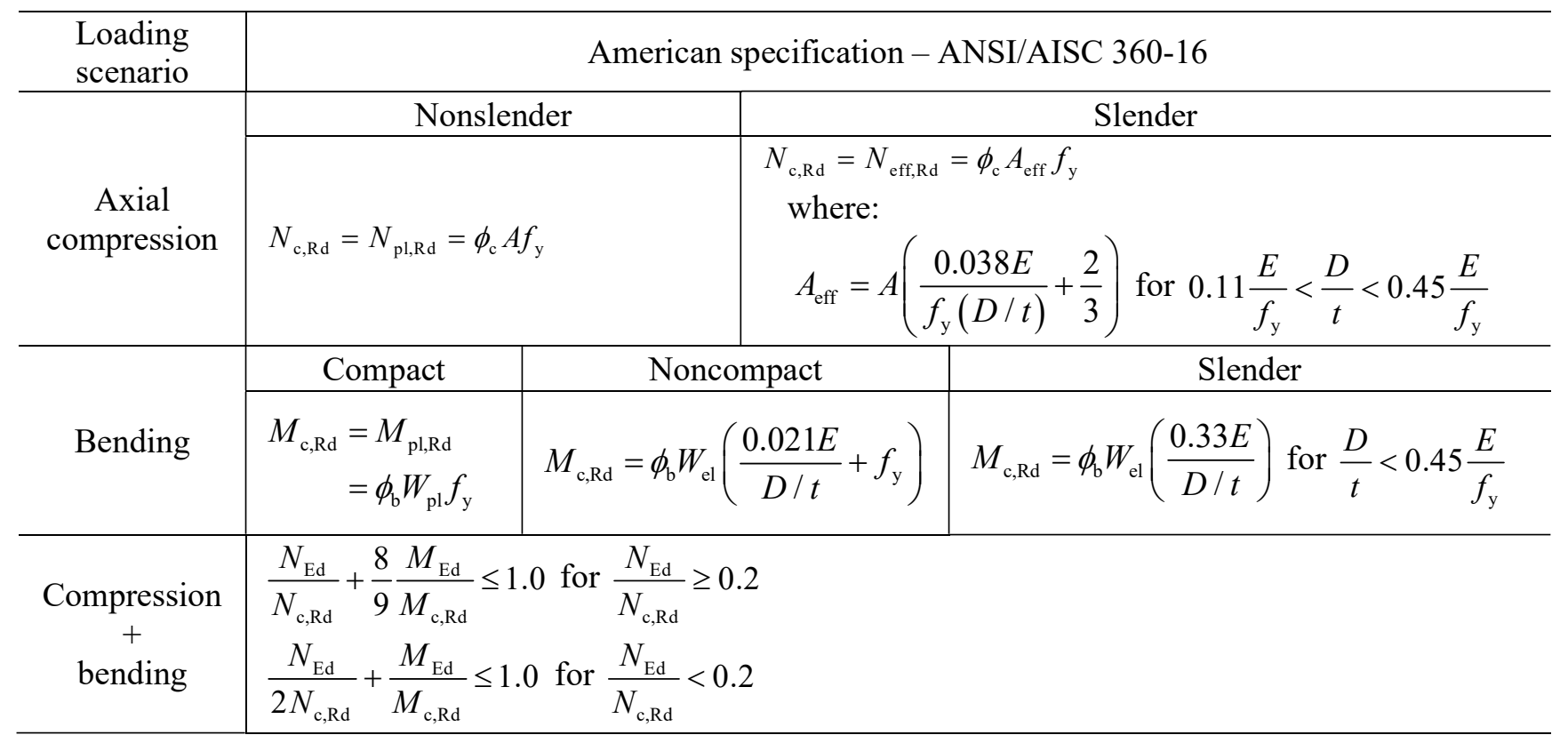


Table 13 Comparison of test and FE results with resistance predictions from EC3 for (a) cold-formed CHS and (b) hot-rolled CHS

(a) Cold-formed CHS

\begin{tabular}{ccccc}
\hline Loading & \multirow{2}{*}{$\begin{array}{c}\text { Evaluation } \\
\text { scenario }\end{array}$} & \multicolumn{3}{c}{$R_{\mathrm{u}} / R_{\mathrm{u}, \mathrm{EC} 3}$} \\
\cline { 3 - 5 } parameter & Class 1-2 & Class 3 & Class 4 \\
\hline Axial & Mean & \multicolumn{2}{c}{1.160} & 1.305 \\
compression & COV & \multicolumn{2}{c}{0.155} & 0.132 \\
\hline Uniform & Mean & 1.071 & 1.167 & 1.309 \\
bending & COV & 0.101 & 0.113 & 0.113 \\
\hline Compression & Mean & 1.230 & 1.299 & 1.497 \\
+ bending & COV & 0.121 & 0.060 & 0.087 \\
\hline
\end{tabular}

(b) Hot-rolled CHS

\begin{tabular}{ccccc}
\hline Loading & \multirow{2}{*}{$\begin{array}{c}\text { Evaluation } \\
\text { scenario }\end{array}$} & \multicolumn{3}{c}{$R_{\mathrm{u}} / R_{\mathrm{u}, \mathrm{EC} 3}$} \\
\cline { 3 - 5 } & parameter & Class 1-2 & Class 3 & Class 4 \\
\hline Axial & Mean & \multicolumn{2}{c}{1.225} & 1.297 \\
compression & COV & \multicolumn{2}{c}{0.186} & 0.138 \\
\hline Uniform & Mean & 1.114 & 1.109 & 1.242 \\
bending & COV & 0.120 & 0.061 & 0.028 \\
\hline Compression & Mean & 1.233 & 1.166 & 1.370 \\
+ bending & COV & 0.157 & 0.052 & 0.073 \\
\hline
\end{tabular}


Table 14 Comparison of test and FE results with resistance predictions from AISC for (a) coldformed CHS and (b) hot-rolled CHS

(a) Cold-formed CHS

\begin{tabular}{|c|c|c|c|c|}
\hline $\begin{array}{l}\text { Loading } \\
\text { scenario }\end{array}$ & $\begin{array}{l}\text { Evaluation } \\
\text { parameter }\end{array}$ & \multicolumn{3}{|c|}{$R_{\mathrm{u}} / R_{\mathrm{u}, \mathrm{AISC}}$} \\
\hline \multirow{3}{*}{$\begin{array}{c}\text { Axial } \\
\text { compression }\end{array}$} & & \multicolumn{2}{|c|}{ Nonslender } & Slender \\
\hline & Mean & \multicolumn{2}{|c|}{1.142} & 1.179 \\
\hline & $\mathrm{COV}$ & \multicolumn{2}{|c|}{0.146} & 0.080 \\
\hline \multirow{3}{*}{$\begin{array}{l}\text { Uniform } \\
\text { bending }\end{array}$} & & Compact & Noncompact & Slender \\
\hline & Mean & 1.079 & 1.126 & 1.327 \\
\hline & $\mathrm{COV}$ & 0.098 & 0.100 & 0.112 \\
\hline \multirow{2}{*}{$\begin{array}{l}\text { Compression } \\
\text { + bending }\end{array}$} & Mean & \multicolumn{3}{|c|}{1.280} \\
\hline & $\mathrm{COV}$ & \multicolumn{3}{|c|}{0.096} \\
\hline
\end{tabular}

(b) Hot-rolled CHS

\begin{tabular}{|c|c|c|c|c|}
\hline $\begin{array}{l}\text { Loading } \\
\text { scenario }\end{array}$ & $\begin{array}{l}\text { Evaluation } \\
\text { parameter }\end{array}$ & \multicolumn{3}{|c|}{$R_{\mathrm{u}} / R_{\mathrm{u}, \mathrm{AISC}}$} \\
\hline \multirow{3}{*}{$\begin{array}{c}\text { Axial } \\
\text { compression }\end{array}$} & & \multicolumn{2}{|c|}{ Nonslender } & Slender \\
\hline & Mean & \multicolumn{2}{|c|}{1.210} & 1.176 \\
\hline & $\mathrm{COV}$ & \multicolumn{2}{|c|}{1.176} & 0.075 \\
\hline \multirow{3}{*}{$\begin{array}{l}\text { Uniform } \\
\text { bending }\end{array}$} & & Compact & Noncompact & Slender \\
\hline & Mean & 1.123 & 1.061 & 1.200 \\
\hline & $\mathrm{COV}$ & 0.118 & 0.048 & 0.106 \\
\hline \multirow{2}{*}{$\begin{array}{l}\text { Compression } \\
\text { + bending }\end{array}$} & Mean & \multicolumn{3}{|c|}{1.215} \\
\hline & $\mathrm{COV}$ & \multicolumn{3}{|c|}{0.079} \\
\hline
\end{tabular}

